\title{
The Singapore Myeloma Study Group Consensus Guidelines for the management of patients with multiple myeloma
}

Sanjay de Mel ${ }^{1, *}$, MRCP, FRCPath, Yunxin Chen ${ }^{2, *}$, MBBS, MRCP, Sathish Kumar Gopalakrishnan ${ }^{2}$ MRCP, FRCPath, Melissa $\underline{O o}^{1}$, MRCP, FRCPath, Constance $\underline{T e O}^{3}$, Msc, Daryl $\underline{T a n}^{4}$, MMed, MRCP, Min Li Claire $\underline{\text { Teo }}{ }^{2}$, MBBS, Allison CY $\underline{T S O}^{5}$, MRCP, FRCPath, Lian King $\underline{\text { Lee }^{5}}$, MRCP, FRCPath, Chandramouli Nagarajan ${ }^{2}$, FRCP, FRCPath, Yeow Tee $\underline{G o h}^{2}$, MBBS, MMed, Wee Joo $\underline{\mathrm{Chng}}^{1}$, FRCP, FRCPath

\begin{abstract}
Multiple myeloma (MM) is an incurable plasma cell neoplasm with an incidence of 100 patients per year in Singapore. Major advances have been made in the diagnosis, risk stratification and treatment of MM in the recent past. The reclassification of a subset of patients with smouldering MM, based on high-risk biomarkers, and the development of the revised international staging system are among the key new developments in diagnosis and staging. The use of novel agent-based treatment has resulted in significant improvements in the survival and quality of life of many patients with MM. Determining the optimal use of proteasome inhibitors, immunomodulators and, more recently, monoclonal antibodies is an area of ongoing investigation. In this guideline, we aim to provide an overview of the management of $\mathrm{MM}$, incorporating the latest developments in diagnosis and treatment.
\end{abstract}

Keywords: evidence-based, guideline, multiple myeloma, Singapore

\section{INTRODUCTION}

Approximately 100 people per year are diagnosed with multiple myeloma (MM) in Singapore. Recent therapeutic advances with novel agents have changed the disease landscape, and while MM was once largely untreatable, patients now have a higher likelihood of entering remission with prolonged survival. These guidelines were developed by the Singapore Myeloma Study Group (SMSG) to provide evidence-based recommendations for the diagnosis and management of MM in the local setting. This guideline is not intended to be prescriptive and should be used in conjunction with physicians' clinical judgement. The guideline is divided into five sections:

I. Diagnosis, staging and risk stratification

II. Supportive care

III. Management of transplant-eligible patients

IV. Management of transplant-ineligible patients

V. Drug toxicity and dose adjustments

\section{METHODS}

The SMSG performed a review of the key literature until 31 December 2015. These included MEDLINE, Cochrane Library and major meeting reports from the American Society of Hematology, American Society of Clinical Oncology, European Society of Hematology and the International Myeloma Workshop. Key recommendations from the International Myeloma Working Group (IMWG) and British Committee for Standards in Haematology have also been incorporated. These were summarised into a draft that the SMSG revised. It also proposed recommendations in situations where there was insufficient published data. We suggest the IMWG guidelines as a reference for readers looking for more details on specific aspects of the management of MM.

\section{DIAGNOSIS, STAGING AND RISK STRATIFICATION \\ Background}

The diagnosis and staging of MM is a rapidly evolving field. The definition of MM in previous IMWG consensus statements required the presence of organ damage, specifically hypercalcaemia, renal impairment, anaemia and bone lesions, commonly recognised by the acronym CRAB. ${ }^{(1)}$ Monoclonal gammopathy of undetermined significance (MGUS) and smouldering multiple myeloma (SMM) are defined by the presence of specific levels of monoclonal protein and clonal bone marrow plasma cells, in the absence of organ involvement, and the majority of these patients progress to develop MM at varying rates. ${ }^{(1)}$

The traditional approach to management of these patients is to withhold treatment until the onset of organ involvement, given the absence of evidence that early treatment impacts outcome. ${ }^{(2)}$ The treatment options for MM have improved significantly over the last ten years. ${ }^{(3)}$ Recent data showed that a subset of patients who lacked organ damage and were classified as SMM according to the previous IMWG criteria have active disease that may benefit from treatment. ${ }^{(4,5)}$ The IMWG has updated its definition of MM to take these changes into account. ${ }^{(6)}$ The following are the key changes made in the 2014 IMWG consensus on diagnosis of MM:

\footnotetext{
'Department of Haematology-Oncology, National University Cancer Institute, National University Health System, ${ }^{2}$ Department of Haematology, Singapore General Hospital, ${ }^{3}$ Division of Oncology Pharmacy, National University Cancer Institute, National University Health System, ${ }^{4}$ Raffles Cancer Centre, Raffles Hospital, ${ }^{5}$ Department of Haematology, Tan Tock Seng Hospital, Singapore

*These two authors contributed equally as first author in this work.

Correspondence: Prof Chng Wee Joo, Senior Consultant, Department of Haematology-Oncology, National University Cancer Institute, National University Health System,
} 1E Kent Ridge Road, NUHS Tower Block Level 7, Singapore 119228. wee_joo_chng@nuhs.edu.sg 
- $\quad$ The presence of $\geq 10 \%$ monoclonal plasma cells in the marrow is a requirement for the diagnosis of MM.

- The presence of a monoclonal protein in the serum or urine is not mandatory to make a diagnosis of MM.

- In the absence of CRAB features, the presence of at least one of three high-risk biomarkers (see next section) is sufficient to establish a diagnosis of MM.

\section{Definition of symptomatic multiple myeloma}

According to the IMWG 2014 consensus, a diagnosis of MM can be made in the presence of monoclonal plasma cells in the bone marrow $(\geq 10 \%)$, or biopsy-proven bony or extramedullary plasmacytoma, and any one or more of the following myelomadefining events:

1. End-organ damage attributable to the underlying plasma cell proliferative disorder:

- Calcium elevation (> $2.75 \mathrm{mmol} / \mathrm{L}$ or $>0.25 \mathrm{mmol} / \mathrm{L}$ above upper limit of the normal)

- Renal dysfunction (creatinine clearance $<40 \mathrm{~mL} / \mathrm{min}$ or serum creatinine $>177 \mu \mathrm{mol} / \mathrm{L}$ )

- Anaemia (haemoglobin $[\mathrm{Hb}]<10 \mathrm{~g} / \mathrm{dL}$ or $>2 \mathrm{~g} / \mathrm{dL}$ below lower limit of the normal)

- Bone disease ( $\geq 1$ osteolytic lesions on skeletal radiography, computed tomography $[\mathrm{CT}]$ or magnetic resonance $[\mathrm{MR}]$ imaging)

2. Any one or more of the following features (biomarkers of high risk):

- Clonal bone marrow plasma cell percentage $\geq 60 \%$

- Involved/uninvolved serum free light chain (SFLC) ratio $\geq 100$

- More than one focal lesion on magnetic resonance imaging studies

\section{Recommendations}

\section{Screening for monoclonal gammopathy}

Although the presence of a monoclonal protein is not mandatory for the diagnosis of $\mathrm{MM}$, approximately $97 \%$ of patients with MM have a monoclonal protein. ${ }^{(6)}$ The finding of a monoclonal protein is also a frequent cause of referrals from other medical specialists who screen patients for monoclonal gammopathies. Serum protein electrophoresis (SPEP) is often used as a screening test to identify a monoclonal protein. Serum immunofixation (IFE) is, however, mandatory to confirm monoclonality. SFLC is important in the diagnosis of patients with light chain MM who may have CRAB features but no evidence of a monoclonal heavy or light chain on SPEP and IFE. SLFC is also relevant for the prognostication of patients with MGUS and to identify patients with 'high-risk SMM', which would now be classified as MM. Furthermore, SFLC plays an important role in the diagnosis of light chain amyloidosis. ${ }^{(7)} \mathrm{We}$ therefore recommend that SPEP, IFE and SFLC be used as screening tests for a monoclonal protein (Box 1). When SPEP, IFE and SFLC are available, screening for a monoclonal protein in urine adds limited diagnostic or prognostic information and we do not recommend its routine use. ${ }^{(7)}$ We recommend using SPEP, IFE and SFLC in the format of a 'screening panel' for the convenience of clinical and laboratory staff. The finding of a monoclonal protein does not confirm the diagnosis of MM. The investigation and management of MGUS and other B-cell neoplasms associated with a monoclonal protein is beyond the scope of this guideline.

\section{Investigations for confirmation of diagnosis and risk stratification}

Bone marrow aspiration and trephine biopsy (BMAT) are mandatory for the diagnosis of MM. Immunohistochemical assessment of light chain restriction on the trephine specimen is recommended to confirm plasma cell clonality. ${ }^{(6)}$ BMAT is especially important in the $3 \%$ of patients with nonsecretory MM who present with CRAB features and no evidence of a monoclonal protein on the screening investigations described above. A full blood count ( $\mathrm{FBC}$ ), serum creatinine levels and calcium levels are essential to confirm the presence of anaemia, renal impairment and hypercalcaemia. Quantification of the serum M-protein by densitometry is recommended at diagnosis, as this provides a baseline for the assessment of treatment response. ${ }^{(8)}$

A whole-body skeletal survey is recommended as the first-line investigation for lytic skeletal lesions. If the skeletal survey shows no lytic lesions, a whole-body low-dose CT (WBLDCT) or MR imaging is recommended if the patient has no other CRAB features. ${ }^{(9)}$ Wholebody MR imaging or WBLDCT is also recommended if the skeletal survey is negative and the patient has symptoms that suggest bone lesions. MR imaging of the spine is indicated if there is a clinical suspicion of spinal cord compression. Whole-body MR imaging is also recommended for all patients diagnosed with SMM, as the finding of a lesion on MR imaging will lead to the diagnosis being reclassified as MM. Positron emission tomography (PET) should be considered in the event that a definitive diagnosis of bone lesions is not possible based on skeletal survey (CT or MR imaging). ${ }^{(6)} \mathrm{MR}$ imaging and PET-CT are also important tools for distinguishing truly solitary bone plasmacytoma from MM by identifying additional occult bone lesions (Box 2).

Risk stratification of MM during the last decade has been based on the international staging system (ISS; Table 1), together with genetic information obtained through bone marrow karyotyping and fluorescent in situ hybridisation, known as the combined genetics-ISS model. ${ }^{(10)}$ The presence of $\mathrm{t}(4 ; 14), 17 \mathrm{p} 13$ deletion (del), $\mathrm{t}(14 ; 16), \mathrm{t}(14 ; 20), 1 \mathrm{p}$ and $1 \mathrm{q}$ abnormalities have been shown to carry an adverse prognosis. While $t(4 ; 14)$ and 17 p13 del have been shown to be adverse across studies, the data for $\mathrm{t}(14 ; 16)$ and chromosome $1 \mathrm{q}$ abnormalities has been more controversial. ${ }^{(10)}$ The revised international staging system (R-ISS), which incorporates the prognostic power of the ISS, genetics and lactate dehydrogenase, has recently been proposed by the IMWG (Table 2). ${ }^{(11)}$ We recommend the use of the R-ISS in routine practice for staging and prognostication.

\begin{tabular}{|c|c|}
\hline 1.1 & Serum protein electrophoresis \\
\hline 1.2 & Serum immunofixation \\
\hline 1.3 & Serum free light chain study \\
\hline
\end{tabular}




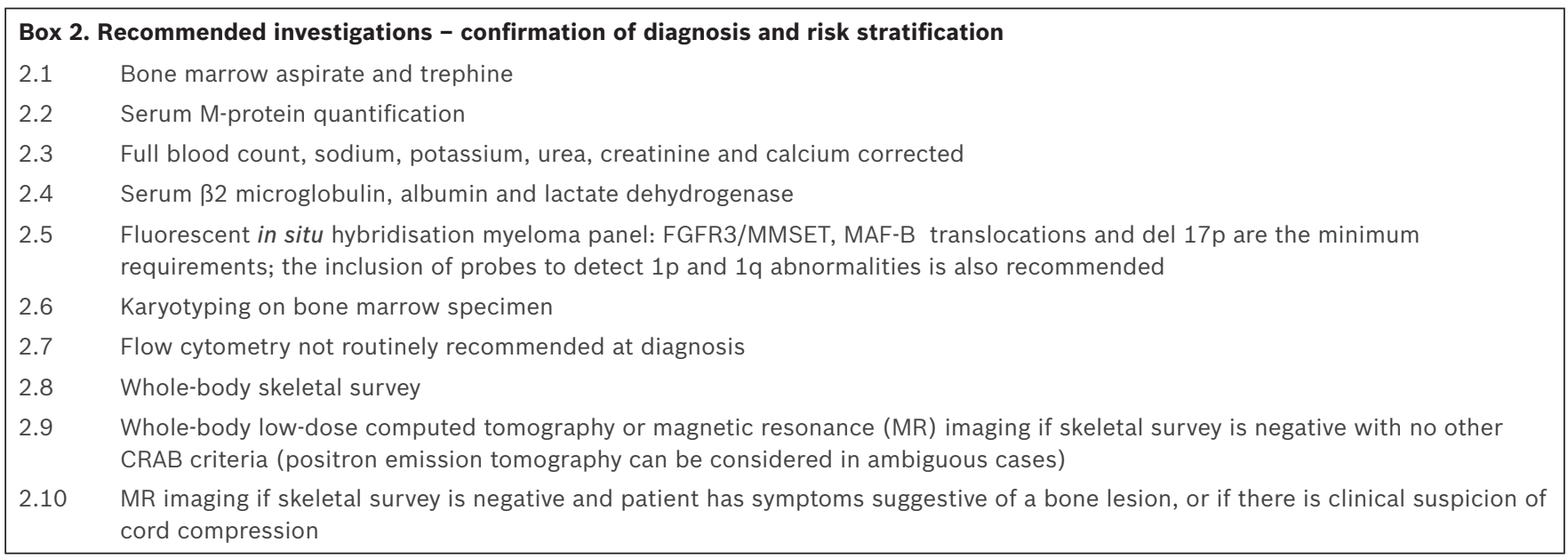

Table 1. International Staging System.

\begin{tabular}{llc}
\hline Stage & Criterion & $\begin{array}{c}\text { Median } \\
\text { survival (mth) }\end{array}$ \\
\hline I & $\begin{array}{l}\text { Serum } \beta 2 \text {-microglobulin }<3.5 \mathrm{mg} / \mathrm{L} \\
\text { and serum albumin } \geq 3.5 \mathrm{~g} / \mathrm{dL}\end{array}$ & 62 \\
II & Not Stage I or III & 44 \\
III & Serum $\beta 2$-microglobulin $\geq 5.5 \mathrm{mg} / \mathrm{I}$ & 29 \\
\hline
\end{tabular}

Table 2. Revised International Staging System (R-ISS).

\begin{tabular}{lccc}
\hline Parameter & $\begin{array}{c}\text { Revised ISS } \\
\text { Stage I }\end{array}$ & $\begin{array}{c}\text { Revised ISS } \\
\text { Stage II }\end{array}$ & $\begin{array}{c}\text { Revised ISS } \\
\text { Stage III }\end{array}$ \\
\cline { 2 - 4 } & $\begin{array}{c}\text { ISS I and no } \\
\text { high-risk CA; } \\
\text { normal LDH }\end{array}$ & $\begin{array}{c}\text { Not R-ISS } \\
\text { stage I or III }\end{array}$ & $\begin{array}{c}\text { ISS III and either } \\
\text { high-risk CA by } \\
\text { FISH* or high LDH }\end{array}$ \\
\hline $\begin{array}{l}\text { 5-year overall } \\
\text { survival (\%) }\end{array}$ & 82 & 62 & 40 \\
\hline
\end{tabular}

*High-risk cytogenetic abnormalities (CA) by FISH defined as deletion $17 \mathrm{p}$ and/or $\mathrm{t}(4 ; 14)$ and/or $\mathrm{t}(14 ; 16)$. FISH: fluorescence in situ hybridisation; $\mathrm{LDH}$ : lactate dehydrogenase

\section{Pre-treatment evaluation}

Pre-treatment evaluation points 1-9, as suggested below, are recommended for all patients with newly diagnosed MM. Point 10, the protocol for financial assessment and assistance, may vary between institutions.

1. Height, weight and body surface area to be recorded

2. Urine human chorionic gonadotropin test for females of childbearing age

3. Liver function tests

4. Viral screen: hepatitis B surface antigen, anti-hepatitis B core total, anti-hepatitis C virus and HIV serology

5. Glucose-6-phosphate dehydrogenase quantification

6. Contraception (use during therapy and for two years after treatment is advised)

7. Dental review (pre-bisphosphonate): patients who have undergone dental extraction should have a two-week rest period prior to commencement of bisphosphonate ${ }^{(12)}$

8. 25-hydroxy vitamin D level

9. Consent for chemotherapy and counselling about treatment regimen and side effects (acute and long-term)
10. Financial assessment and referral to social worker for bortezomib and lenalidomide

\section{Conclusion}

Our knowledge of the biology of MM has increased rapidly over the last decade. Therefore, the diagnosis and prognostication of MM has evolved significantly, with a number of clinical and genetic parameters proving to be of prognostic use. It is noteworthy, however, that selected investigations (such as those used in the R-ISS) can provide accurate prognostication at a reasonable cost. There is little doubt that the diagnosis and risk stratification of MM will further evolve in the near future, allowing for more targeted and risk-adapted therapeutic approaches. ${ }^{(13)}$

\section{SUPPORTIVE CARE}

\section{Introduction}

Holistic care for patients with MM goes beyond offering the best available anti-myeloma treatment options to patients. While MM is still incurable, novel therapies have vastly improved the response rates and options available to patients following relapses, hence improving survival. ${ }^{(12)}$ With improved lifespans, patients with $\mathrm{MM}$ have become more vulnerable to the cumulative toxicity of treatments. The symptom burden in this group of patients may not necessarily be improved with the introduction of more anti-myeloma treatment options. The important role of supportive care, to ensure that these patients remain minimally affected by the complications of disease and treatment, should not be overlooked, for it ensures that their quality of life is not compromised.

\section{Complications related to multiple myeloma}

The incidence of MM-related organ and tissue involvement at initial presentation is summarised in Table $3 .{ }^{(14)} \mathrm{We}$ propose the following recommendations for the supportive management of patients with MM, in conjunction with references to published guidelines. ${ }^{(15,16)}$ The measures suggested here may be undertaken to ameliorate the effects of MM-related complications, as well as to prevent further morbidities. 
Table 3. Incidence of myeloma-related organ and tissue involvement at diagnosis. ${ }^{(3)}$

\begin{tabular}{lc}
\hline Complication & Incidence (\%) \\
\hline Anaemia $(\mathrm{Hb}<12 \mathrm{~g} / \mathrm{dL})$ & 65 \\
Hypercalcaemia $\left(\mathrm{Ca}^{2+}>2.75 \mathrm{mmol} / \mathrm{L}\right)$ & 23 \\
Renal impairment $(\mathrm{Cr}>180 \mathrm{umol} / \mathrm{L})$ & 13 \\
Bone lesions & 75 \\
\hline
\end{tabular}

Ca: calcium; Cr: creatinine; Hb: haemoglobin

\section{Hypercalcaemia}

Osteoclast-mediated bone destruction in MM may lead to hypercalcaemia. It has a broad spectrum of clinical manifestations ranging from polydipsia, polyuria and abdominal pain to renal and even neurological deficits, including coma and obtundation. ${ }^{(17)}$ When other causes of hypercalcaemia have been excluded, definitive treatment for MM should be undertaken without delay. Supportive therapy should also be commenced while awaiting a response to the definitive therapy.

Hydration with intravenous normal saline is usually adequate for mild hypercalcaemia $\left(\mathrm{Ca}^{2+}=2.6-2.9 \mathrm{mmol} / \mathrm{L}\right)$. For moderate to severe hypercalcaemia $\left(\mathrm{Ca}^{2+}>2.9 \mathrm{mmol} / \mathrm{L}\right)$, bisphosphonates should be given in addition to hydration. In the treatment of malignancy-related hypercalcaemia, intravenous zoledronic acid $4 \mathrm{mg}$ was found to be superior to intravenous pamidronate in resolving hypercalcaemia. ${ }^{(18)}$ Close monitoring of fluid balance and expectant diuresis should also be considered. ${ }^{(15)}$

\section{Renal complications}

Renal impairment in MM patients occurs as a result of light chain medicated damage of renal tubules, together with a combination of hypercalcaemia, infections and use of nephrotoxic agents. ${ }^{(19)}$ In patients presenting with renal impairment, there is a pressing need to curtail further worsening of renal function and possibly reverse renal insults, in order to avoid the need for long-term renal replacement therapy. To prevent further worsening of renal function, hydration should be optimised and nephrotoxic agents avoided. Early institution of anti-myeloma treatment has the largest impact on reversal of renal damage, as it can reverse myeloma-related renal complications in up to $50 \%$ of patients. ${ }^{(20)}$ This hinges upon attaining an accurate diagnosis and degree of light chain involvement as soon as possible. Bortezomib with high-dose dexamethasone has been found to be effective in this setting. ${ }^{(20)}$

At the time of publication, there is insufficient evidence to support the role of plasma exchange or high cut-off dialysis in patients with suspected light chain cast nephropathy. A metaanalysis of 147 patients with MM and renal failure suggested improved renal outcome in patients treated with chemotherapy and plasmapheresis, rather than chemotherapy alone. ${ }^{(21)}$ Small cohort studies reported sustained renal recovery and dialysis independence in $75 \%$ of patients with renal impairment who were placed on high cut-off dialysis. ${ }^{(22)}$ However, larger-scale studies are required to provide conclusive guidelines on the use of plasmapheresis or high cut-off dialysis in MM patients with severe renal impairment.

\section{Anaemia}

Anaemia is a frequent complication in MM and may significantly impair patients' quality of life. ${ }^{(23,24)}$ After exclusion of haematinic deficiency or blood loss, patients with persistent $\mathrm{Hb}<10 \mathrm{~g} / \mathrm{dL}$ should receive treatment for anaemia attributable to myeloma. A therapeutic trial of an erythropoiesis-stimulating agent may be administered, with the aim to increase $\mathrm{Hb}$ levels without exceeding $12 \mathrm{~g} / \mathrm{dL}$. Subcutaneous erythropoietin alfa 40,000 units or erythropoietin beta 30,000 units per week may be used at the start of the therapy. ${ }^{(15)}$ Effective treatment of anaemia with erythropoietin effectively decreases transfusion requirements and improves quality of life. ${ }^{(23)}$ Erythropoietin can be stopped if no response is observed after 6-8 weeks.

\section{Management of bone disease and related complications}

MM bone disease often results in pain, pathologic fractures and spinal cord compression. ${ }^{(14)}$ Long bone fractures require stabilisation and consideration of subsequent radiotherapy. Local radiotherapy with $8 \mathrm{~Gy}$ in a single fraction has been shown to be useful for pain relief. ${ }^{(25)}$ An orthopaedic opinion should be sought to consider pre-emptive surgery for any large lytic lesion that may potentially cause instability. If there is any clinical suspicion of spinal cord compression, urgent MR imaging of the spine should be performed and orthopaedic surgeons consulted regarding the need for immediate surgical intervention. Dexamethasone $40 \mathrm{mg}$ daily should be commenced in addition to spinal nursing. Adjunctive radiotherapy may be employed to control tumour growth and prevent irreversible neurological damage. ${ }^{(26)}$

All patients with symptomatic MM, regardless of the presence of bone lesions, should be treated with a bisphosphonate, the first choice being zoledronic acid. Beyond its role in bone health, zoledronic acid has been shown to have anti-cancer activity in myeloma, with improvements to overall survival seen in patients on treatment. (27) Pamidronate is an option in patients with a creatinine clearance of $<30 \mathrm{~mL} / \mathrm{min}$. A dose of $30 \mathrm{mg}$ monthly is suggested. The minimum duration of bisphosphonate therapy is two years, on the condition that a very good partial response (VGPR) or complete response (CR) is achieved. Bisphosphonates should be restarted at the time of relapse. ${ }^{(12)}$

Denosumab, a human monoclonal antibody against the receptor activator of nuclear factor kappa-B ligand, has been demonstrated to reduce bone-related events in patients as effectively as zoledronic acid. ${ }^{(28)}$ Bisphosphonate, but not denosumab, deposits in bone with a long half-life, which may make a difference in long-term efficacy as well as adverse effects. ${ }^{(29)}$ Randomised trials comparing denosumab with zoledronic acid in MM are still in progress. Denosumab is, therefore, not recommended outside the context of a clinical trial at this point.

We recommend the measurement of 25-hydroxy vitamin D levels in all patients at diagnosis. Vitamin D and calcium replacement is indicated in patients with vitamin D deficiency or those on bisphosphonate treatment. It is contraindicated in patients with hypercalcaemia. The recommended daily dose for replacement is calcium 1,500 $\mathrm{mg}$ and vitamin D 1,000 IU. ${ }^{(30}$ 


\section{Infective complications}

The combination of disease-related hypogammaglobulinaemia and treatment-related immunosuppression increases susceptibility to and severity of infections in MM patients. ${ }^{(15)}$ Antiviral prophylaxis using acyclovir is recommended for patients receiving proteasome inhibitors (PI), and anti-Pneumocystis jiroveci pneumonia prophylaxis is recommended for patients receiving high-dose steroids. ${ }^{(31,32)}$ The routine use of antibacterial and antifungal prophylaxis in MM patients cannot be recommended at the time of publication.

Prophylactic intravenous immunoglobulin may also be considered for patients in the plateau phase with hypogammaglobulinaemia and recurrent bacterial infections. We recommend intravenous immunoglobulin $0.4 \mathrm{~g} / \mathrm{kg}$ monthly for six months in patients with $>2$ significant infective episodes per year. ${ }^{(33)}$ Prophylactic antiviral therapy for hepatitis B carriers and management of neutropenic fever should be carried out according to institutional protocols.

\section{Thrombotic complications}

Although patients with active malignancy have a higher risk of thromboembolic complications, current guidelines do not advocate routine thromboprophylaxis for patients with malignancy. ${ }^{(34)}$ The use of immunomodulators, such as thalidomide and lenalidomide, increases the risk of venous thromboembolism in patients with MM, especially when used in combination with steroids or chemotherapy. ${ }^{(35,36)}$ A metaanalysis performed on the thromboembolic risks of thalidomide and lenalidomide in MM patients demonstrated that the highest risk occurs in patients with newly diagnosed MM receiving thalidomide and dexamethasone without thromboprophylaxis. The three-month venous thromboembolism risk is $12 \%$ in this group. In other MM patients treated with thalidomide or lenalidomide, the venous thromboembolism risk was $3 \%-5 \%$. $^{(37)}$

There are no randomised trials comparing the treatment outcome of MM patients on thalidomide or lenalidomide with and without thromboprophylaxis. Moreover, there are insufficient observations regarding the risk of major bleeding on thromboprophylaxis. There are also no head-to-head comparisons between the various forms of anticoagulants (low-molecularweight heparin vs. aspirin vs. target-specific oral anticoagulants). Some guidelines are based on extrapolations from other risk groups; hence, there is no available evidence-based guideline on the use of thromboprophylaxis in patients with MM who are treated with thalidomide and lenalidomide. While the IMWG recommends risk assessment, this approach has not been validated. It has been suggested that the use of prophylaxis may confer decreased risk, but no clear benefit has been proven.

The SMSG proposes the following recommendation with reference to the risk assessment model suggested by the IMWG (Table 4). ${ }^{(35)}$ Patients should receive thromboprophylaxis for the first six months of treatment, until disease control is achieved, or for as long as the risk of thromboembolism remains high. In addition, the following are recommended:
Table 4. Risk factors for venous thromboembolism (VTE) in multiple myeloma patients. ${ }^{(15)}$

\begin{tabular}{|c|c|}
\hline Type & Factor \\
\hline \multicolumn{2}{|l|}{ Individual } \\
\hline Obesity & Body mass index $\geq 30 \mathrm{~kg} / \mathrm{m}^{2}$ \\
\hline Comorbidity & $\begin{array}{l}\text { Cardiac disease; renal disease; diabetes } \\
\text { mellitus; blood clotting disorders/previous } \\
\text { VTE; acute infection; immobilisation }\end{array}$ \\
\hline Surgical issue & General surgery/anaesthesia; trauma \\
\hline Medication & Erythropoietin \\
\hline \multicolumn{2}{|l|}{ Myeloma-related } \\
\hline Disease factor & $\begin{array}{l}\text { Hyperviscosity; high dose dexamethasone } \\
\text { (> } 480 \mathrm{mg} \text { dexamethasone equivalent/mth); } \\
\text { doxorubicin; multi-agent chemotherapy }\end{array}$ \\
\hline
\end{tabular}

- For all newly diagnosed MM patients treated with thalidomide or lenalidomide, consider aspirin prophylaxis.

- $\quad$ For all MM patients treated with thalidomide or lenalidomide in combination with steroids or chemotherapy, consider aspirin prophylaxis.

- $\quad$ For all MM patients on thalidomide or lenalidomide with $\geq 2$ other risk factors, consider low-molecular-weight heparin at prophylactic dose.

It is noteworthy that the incidence of venous thromboembolism in Asian MM patients on thalidomide and lenalidomide may be less than that of their western counterparts. ${ }^{(38,39)}$ These recommendations should, therefore, be considered in this context, and the risk and benefit of anticoagulation assessed on a caseby-case basis.

\section{Conclusion}

Care of the patient with MM requires attention to factors beyond disease status. Attention to disease and treatment-related complications, as well as collaboration among primary care physicians, other specialists and haematologists, will ensure holistic patient care and maximise the benefits from treatment. Our recommendations for supportive care in MM are summarised in Table 5.

\section{MANAGEMENT OF TRANSPLANT- ELIGIBLE PATIENTS}

\section{Background}

Approximately $35 \%$ of patients with MM are below 65 years of age. ${ }^{(40)}$ High-dose therapy followed by autologous stem cell transplantation (ASCT) has been shown to prolong survival in both the pre-novel agent and novel agent eras. ${ }^{(41,42)}$ In this consensus statement, we summarise the evidence for treatment of transplanteligible patients with $\mathrm{MM}$ and provide recommendations on the optimal treatment options.

\section{Definition of transplant eligibility}

Patients below 65 years of age with an acceptable comorbidity profile and performance status are considered transplanteligible. ${ }^{(43)}$ Selected patients aged above 65 years with good performance status and minimal comorbidities may be considered for reduced-intensity transplant. ${ }^{(44,45)}$ 
Table 5. Summary of recommendations for supportive care of patients with multiple myeloma.

\begin{tabular}{|c|c|c|}
\hline Parameter & Recommendation & Comment \\
\hline \multicolumn{3}{|l|}{ Hypercalcaemia } \\
\hline Mild & IV normal saline & Monitor fluid status \\
\hline Moderate-severe & IV normal saline & Monitor fluid status \\
\hline $\mathrm{CrCl}>30 \mathrm{~mL} / \mathrm{min}$ & $\begin{array}{l}\text { IV zoledronic acid } \\
4 \mathrm{mg} \text { over } 15 \mathrm{~min}\end{array}$ & $\begin{array}{l}\text { Suggested dose adjustment for renal impairment: } \\
\text { - } \mathrm{CrCl} 50 \text { to } 60 \mathrm{~mL} / \mathrm{min} \text { : Reduce dose to } 3.5 \mathrm{mg} \\
\text { - } \mathrm{CrCl} 40 \text { to } 49 \mathrm{~mL} / \mathrm{min} \text { : Reduce dose to } 3.3 \mathrm{mg} \\
\text { - } \mathrm{CrCl} 30 \text { to } 39 \mathrm{~mL} / \mathrm{min} \text { : Reduce dose to } 3 \mathrm{mg} \\
\text { - } \mathrm{CrCl}<30 \mathrm{~mL} / \mathrm{min} \text { : Use is not recommended } \\
\text { Consider IV pamidronate if significant renal impairment }\end{array}$ \\
\hline $\mathrm{CrCl}<30 \mathrm{~mL} / \mathrm{min}$ & $\begin{array}{l}\text { IV pamidronate } \\
30 \mathrm{mg} \text { over } 4-6 \mathrm{hr}\end{array}$ & $\begin{array}{l}\text { Limited pharmacokinetic data in patients with } \mathrm{CrCl}<30 \mathrm{~mL} / \mathrm{min} \\
\text { Suggested dose for } \mathrm{CrCl}<30 \mathrm{~mL} / \mathrm{min} \text { and extensive bone } \\
\text { disease: } 90 \mathrm{mg} \text { over } 4-6 \text { hours } \\
\text { Consider reduced initial dose if renal impairment is pre-existing }\end{array}$ \\
\hline \multicolumn{3}{|l|}{ Renal impairment } \\
\hline \multirow[t]{3}{*}{ All patients with renal impairment } & Optimise hydration & \\
\hline & Avoid nephrotoxic agents & \\
\hline & $\begin{array}{l}\text { Definitive treatment for } \\
\text { MM }\end{array}$ & Bortezomib-based therapy recommended \\
\hline Requiring RRT with high SFLC & $\begin{array}{l}\text { Consider plasmapheresis } \\
\text { or } \mathrm{HCO} \text { dialysis }\end{array}$ & $\begin{array}{l}\text { Not evidence-based } \\
\text { Consider on case-by-case basis }\end{array}$ \\
\hline \multicolumn{3}{|l|}{ Anaemia } \\
\hline $\mathrm{Hb}<10 \mathrm{~g} / \mathrm{L}$ & Erythropoietin & $\begin{array}{l}\text { To start at S/C erythropoietin alfa } 40,000 \text { units or S/C } \\
\text { erythropoietin beta } 30,000 \text { units/wk } \\
\text { Not to exceed } \mathrm{Hb}<12 \mathrm{~g} / \mathrm{L} \\
\text { Consider stopping therapeutic trial if no response after } 6-8 \mathrm{wk}\end{array}$ \\
\hline Bone protection & Monthly zoledronic acid & See above for dosage adjustment for $\mathrm{CrCl}$ \\
\hline \multicolumn{3}{|l|}{ Infective complication } \\
\hline \multicolumn{3}{|l|}{ Antimicrobial prophylaxis } \\
\hline Bortezomib & Acyclovir prophylaxis & \\
\hline High-dose steroid & Cotrimoxazole prophylaxis & \\
\hline$>2$ infective episodes/yr & IVIG & Consider monthly IVIG $0.4 \mathrm{~g} / \mathrm{kg}$ for $6 \mathrm{mth}$ \\
\hline \multicolumn{3}{|l|}{ Thromboprophylaxis } \\
\hline $\begin{array}{l}\text { Newly diagnosed MM treated with } \\
\text { thalidomide/lenalidomide }\end{array}$ & PO Aspirin 100 mg OM & \\
\hline $\begin{array}{l}\text { MM patients treated with } \\
\text { thalidomide/lenalidomide } \\
\text { in combination with } \\
\text { steroids/chemotherapy }\end{array}$ & PO Aspirin 100 mg OM & \\
\hline $\begin{array}{l}\text { MM on thalidomide/lenalidomide } \\
\text { with } \geq 2 \text { other risk factors }\end{array}$ & $\begin{array}{l}\text { LMWH at prophylactic } \\
\text { dose }\end{array}$ & \\
\hline
\end{tabular}

$\mathrm{CrCl}$ : creatinine clearance; Hb: haemoglobin; HCO: high cut-off; IVIG: intravenous immunoglobulin; LMWH: low-molecular-weight heparin; MM: multiple myeloma; OM: once per day; PO: per oral; RRT: renal replacement therapy; RT: radiotherapy; S/C: subcutaneous; SFLC: serum free light chain

\section{Indications for treatment}

Clinical features defining symptomatic MM and/or one or more of the three high-risk biomarkers in patients who would previously have been classified as SMM are considered treatment indications. ${ }^{(5,6)}$ Clinical features defining symptomatic MM and high-risk biomarkers are described in detail in Section I.

\section{Response definitions}

The response definitions are based on the uniform response criteria recommended by the IMWG, as summarised in Table $6 .{ }^{(8)}$

\section{Choice of induction therapy}

Cavo et al demonstrated that bortezomib, thalidomide and dexamethasone (VTD) produced a significantly higher rate 
Table 6. International Myeloma Working Group definitions of response categories.

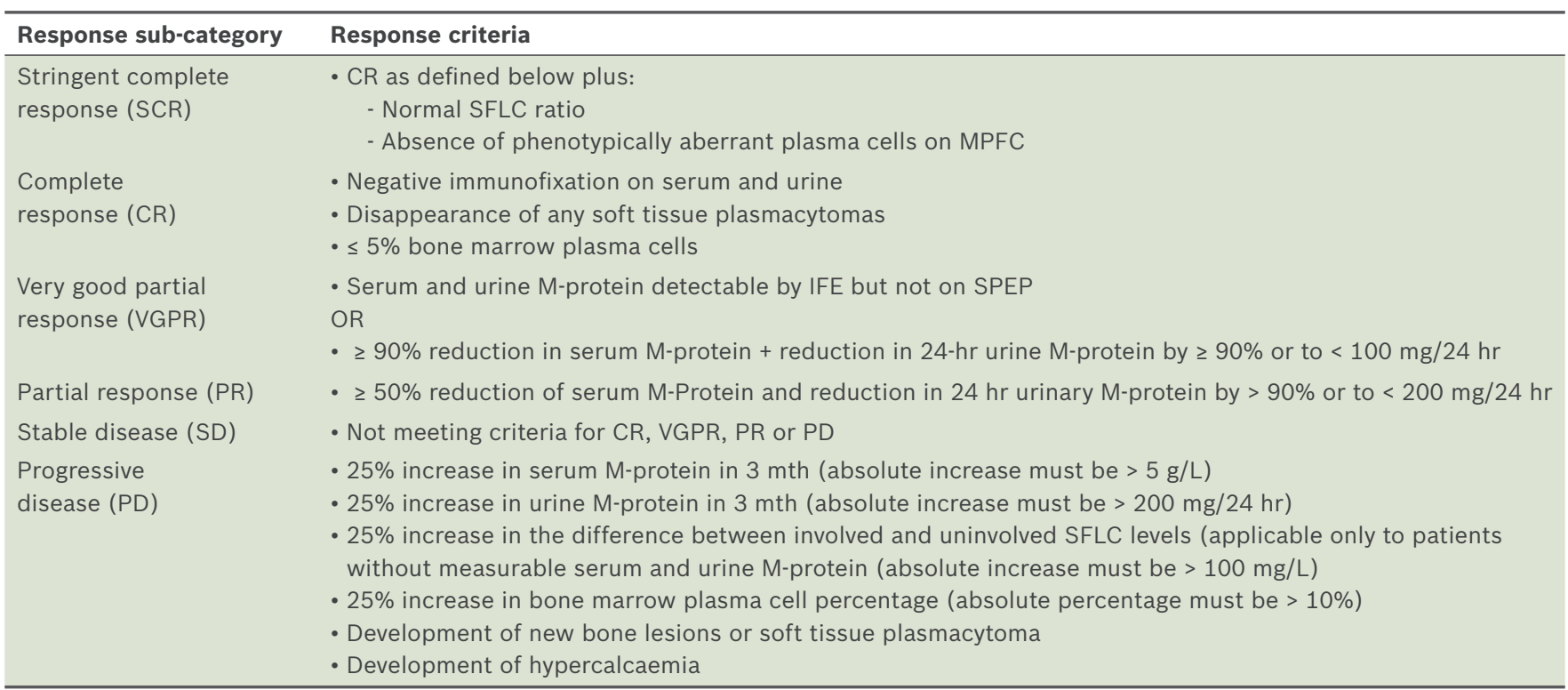

IFE: immunofixation; MPFC: multiparameter flow cytometry; SFLC: serum free light chain; SPEP: serum protein electrophoresis

of complete remission before stem cell transplantation (SCT) compared to thalidomide and dexamethasone. ${ }^{(46)}$ Bortezomib, cyclophosphamide and dexamethasone (VCD) has also been shown to produce impressive response rates and survival. ${ }^{(47,48)}$ A meta-analysis of Phase 3 trials comparing bortezomib and non-bortezomib-containing induction regimens showed a superior response rate and progression-free survival (PFS) for the bortezomib-containing regimens. ${ }^{(49)}$ Therefore, we recommend that PI-based induction should be considered in all patients.

There is growing evidence that VTD may be superior to VCD. This was shown in a retrospective analysis by Leiba et al ${ }^{(50)}$ and, more recently, in a prospective randomised study by the Intergroupe Francophone du Myelome (IFM). ${ }^{(51)}$ At present, we would recommend both VTD and VCD as options for induction therapy, depending on the physician's choice. If PI-based induction therapy is not possible, at least one novel agent should be a component of the induction regimen. ${ }^{(4))}$ The bortezomib, lenalidomide and dexamethasone (VRD) regimen has shown activity in high-risk patients, ${ }^{\left({ }^{52,53)}\right.}$ but has not been shown to be superior to VCD or VTD. VRD may be considered in certain high-risk patients, although the significant cost of this protocol should also be considered.

We suggest the following protocols as options for Pl-based induction therapy:

- $\quad$ Bortezomib, thalidomide and dexamethasone, i.e. VTD $(\text { Table } 7)^{(46)}$

- Bortezomib, cyclophosphamide and dexamethasone, i.e. VCD (Table 8, modified from Reeder et $\mathrm{a}^{\left({ }^{(47)}\right)}$

- $\quad$ Bortezomib, lenalidomide and dexamethasone, i.e. VRD $(\text { Table } 9)^{(52,53)}$

\section{Options for patients for whom proteasome inhibitor- based induction therapy is not possible}

The intensive therapy arm of the UK Medical Research Council (MRC) IX study showed that cyclophosphamide, thalidomide and dexamethasone (CTD) was superior to cyclophosphamide, vincristine, doxorubicin and dexamethasone in terms of response rate. ${ }^{(54)}$ For patients who, for whatever reason, are not able to receive PI-based induction, we recommend that at least one novel agent be included in the induction regimen.

We recommend the following treatment protocols as options when Pl-based induction is not possible:

- $\quad$ Cyclophosphamide, thalidomide and dexamethasone, i.e. CTD (Table 10). ${ }^{(54)}$ (Dexamethasone dose is lower than that used in the original study [Days 1-4 and 12-15], based on data of increased mortality with higher doses of dexamethasone. $)^{(55)}$

- $\quad$ Thalidomide and dexamethasone, i.e. TD (Table 11). ${ }^{(56)}$ (Dexamethasone dose is lower than that used in the original study [Days 1-4, 9-12 and 17-20], based on data of increased mortality with higher doses of dexamethasone. $)^{(55)}$

\section{Number of cycles of induction and response before stem cell harvest}

The depth of response pre-transplant correlates with event-free survival and overall survival, with patients who show a CR having the best outcome. ${ }^{(57,58)}$ The minimum response required before proceeding to ASCT is a partial response (PR). If a PR is not achieved after four cycles of induction therapy, a further two cycles should be considered. If a PR is not achieved after six cycles or there is progressive disease at any time point during induction, a change of therapy is recommended. ${ }^{(12,40)}$

\section{Mobilisation chemotherapy and stem cell collection}

High-dose cyclophosphamide (Cy) at 4-7 g/ $\mathrm{m}^{2}$ with granulocyte colony-stimulating factor (GCSF) has been shown to be effective for haematopoietic progenitor cell mobilisation despite associated haematologic toxicity. ${ }^{(59)}$ Vinorelbine $25 \mathrm{mg} / \mathrm{m}^{2}$ in combination with Cy $1,500 \mathrm{mg} / \mathrm{m}^{2}$ (Vino-Cy) was shown to be comparable to Cy mobilisation in a study using historical controls. ${ }^{(12,60)}$ We recommend one of the following mobilisation protocols: 
Table 7. VTD (bortezomib, thalidomide and dexamethasone) protocol.

\begin{tabular}{lllc}
\hline Day & Drug & Route & Dose \\
\hline $\begin{array}{l}\text { 1-28 or } \\
1-21\end{array}$ & Thalidomide & Per os & $100-200 \mathrm{mg}$ \\
$\begin{array}{l}\text { 1, 8, 15, } \\
\text { 22 or } 1,4,\end{array}$ & Bortezomib & Subcutaneous & $1.3 \mathrm{mg} / \mathrm{m}^{2}$ \\
8,11 & & \\
$\begin{array}{l}1,2,8,9, \\
15,16,22,\end{array}$ & Dexamethasone & Per os & $40 \mathrm{mg}$ \\
23 or 1,2, & & & \\
$4,5,8,9$, & & & \\
11,12 & & & \\
\hline
\end{tabular}

Cycle length: 28 days for weekly bortezomib. Subcutaneous bortezomib should be used in all patients. Intravenous bortezomib and twice-weekly dosing may be considered in patients who require a rapid reduction in paraprotein level, e.g. patients with renal impairment.

Table 8. VCD (bortezomib, cyclophosphamide and dexamethasone) protocol.

\begin{tabular}{lllc}
\hline Day & Drug & Route & Dose \\
\hline $1,8,15,22$ & Cyclophosphamide & Per os & $300 \mathrm{mg} / \mathrm{m}^{2}$ \\
$1,8,15,22$ & Bortezomib & Subcutaneous & $1.3 \mathrm{mg} / \mathrm{m}^{2}$ \\
$1,8,15,22$ & Dexamethasone & Per os & $40 \mathrm{mg}$ \\
\hline
\end{tabular}

Cycle length: 28 days. Bortezomib $1.3 \mathrm{mg} / \mathrm{m}^{2}$ on Days $1,4,8$ and 11 can be considered in patients requiring a rapid reduction in paraprotein level and rena impairment. If bortezomib is given twice weekly, the dexamethasone dose should be $40 \mathrm{mg}$ daily on Days 1-4, 9-12 and 17-20.

Table 9. VRD (bortezomib, Ienalidomide and dexamethasone) protocol.

\begin{tabular}{lllc}
\hline Day & Drug & Route & Dose \\
\hline $1-14$ & Lenalidomide & Per os & $25 \mathrm{mg}$ \\
$1,4,8,11$ & Bortezomib & Subcutaneous & $1.3 \mathrm{mg} / \mathrm{m}^{2}$ \\
$1,8,15$ or & Dexamethasone & Per os & $40 \mathrm{mg}$ \\
${ }^{* 1-5 \text { and 8-12 }}$ & & & \\
\hline
\end{tabular}

Cycle length: 21 days. To be considered in high-risk patients with aggressive disease. *If dexamethasone is given on Days 1-5 and 8-12, dosing for Cycles $1-4$ should be $20 \mathrm{mg}$ and $10 \mathrm{mg}$ for subsequent cycles. ${ }^{(53,77)}$

Table 10. CTD (cyclophosphamide, thalidomide and dexamethasone) protocol.

\begin{tabular}{lllc}
\hline Day & Drug & Route & Dose \\
\hline $1,8,15$ & Cyclophosphamide & Per os & $500 \mathrm{mg}$ \\
$1-21$ & Thalidomide & Per os & $100 \mathrm{mg}$ \\
$1,8,15$ & Dexamethasone & Per os & $40 \mathrm{mg}$ \\
\hline
\end{tabular}

Cycle length: 21 days. Dexamethasone dose is lower than that used in the original study (1-4 and 12-15), based on data of increased mortality with higher doses of dexamethasone. ${ }^{(55)}$

Table 11. TD (thalidomide and dexamethasone) protocol.

\begin{tabular}{lllc}
\hline Day & Drug & Route & Dose \\
\hline $1-28$ & Thalidomide & Per os & $100 \mathrm{mg}$ \\
$1,8,15,22$ & Dexamethasone & Per os & $40 \mathrm{mg}$ \\
\hline
\end{tabular}

Cycle length: 28 days. Dexamethasone dose is lower than that used in the original study $(1-4,9-12,17-20)$, based on data of increased mortality with higher doses of dexamethasone. ${ }^{(55)}$

(a) vinorelbine $25 \mathrm{mg} / \mathrm{m}^{2}$ on Day 1, Cy 1,500 $\mathrm{mg} / \mathrm{m}^{2}$ on Day 2 and pegylated GCSF $6 \mathrm{mg}$ on Day 4; or (b) Cy 1,500 mg/m² on Days 1 and 2 and GCSF 10 mcg/kg/day from Day 5 onwards.
A haematopoietic progenitor cell collection adequate for two SCTs should be the target; this is conventionally accepted to be greater than $5 \times 10^{6}$ per $\mathrm{kg} /$ body weight. ${ }^{(61)}$

\section{Conditioning regimen}

ASCT is the standard of care for transplant-eligible patients with MM. This was demonstrated in two pivotal randomised studies in the pre-novel agent era, as well as two studies in the novel agent era. ${ }^{(41-43,62)}$ Melphalan $200 \mathrm{mg} / \mathrm{m}^{2}$ is the standard conditioning regimen. ${ }^{(41)}$ The addition of bortezomib to melphalan conditioning was shown in a Phase II study to be associated with higher CR rates compared to historical controls. ${ }^{(63)}$ However, there is no randomised trial data to show the benefit of this combination, and thus we do not recommend it outside of clinical trials.

Single versus double autologous stem cell transplantation A randomised study by the IFM showed that tandem ASCT results in overall survival benefit for patients who achieved less than a VGPR after their first ASCT. ${ }^{(64)}$ This study was, however, in the pre-novel agent era, and there is limited data to support this practice in the novel agent era. Tandem ASCT should not be routinely offered, but instead considered only in patients who have achieved less than a VGPR after their first ASCT, especially in patients with high-risk disease.

\section{Disease monitoring}

We recommend that the following parameters be monitored after each cycle of treatment: ${ }^{(12)} \mathrm{M}$-protein level; $\mathrm{FBC}$; renal function; calcium; immunoglobulin level (if immunoglobulin A MM); SFLC level (instead of $M$-protein quantification and immunoglobulin level) for light chain myeloma; and bone marrow studies if aiming to confirm CR or investigate unexplained cytopenia.

\section{Role of consolidation therapy}

As there is no clear evidence of an overall survival benefit from bortezomib or lenalidomide consolidation, they are not routinely recommended. Bortezomib and lenalidomide have both been shown to prolong PFS and are therefore options for consolidation in selected patients; in those with only a PR after ASCT, two further cycles of a regimen similar to the induction can be given for consolidation. ${ }^{(65,66)}$

\section{Role of maintenance therapy}

Lenalidomide maintenance has been shown to prolong PFS and overall survival after ASCT in one randomised clinical trial. ${ }^{(67)}$ It should, therefore, be considered an option for patients after a thorough discussion of the risks, benefits and costs. In view of the risk of second primary malignancy, the duration of lenalidomide maintenance should be limited to two years. Thalidomide maintenance has also been shown to prolong PFS after ASCT in patients who achieved less than a VGPR. ${ }^{(68)}$ Thus, it may be considered in patients who have achieved less than a VGPR after ASCT. The duration of thalidomide maintenance should be limited to one year in view of the risk of neuropathy. ${ }^{(69)}$ 
Single-agent bortezomib maintenance has only been assessed in one prospective Phase III study where the standard arm was treated with vincristine, adriamycin, dexamethasone induction, high-dose therapy and thalidomide maintenance. It is, therefore, not possible to recommend bortezomib maintenance outside of a clinical trial at this point. ${ }^{(42)}$

\section{Role of allogeneic transplant}

Allogeneic SCT is currently the only curative therapy available for $\mathrm{MM}$; however, it is associated with high transplant-related mortality of $20 \%-30 \% .{ }^{(70)}$ Allogeneic SCT may be considered in an upfront setting or at first relapse for young, fit patients with high-risk disease, especially $17 \mathrm{p}$ del. Patients who are very young (e.g. < 40 years) with standard-risk disease are another group for whom this approach is a consideration. ${ }^{(71)}$

\section{Conclusion}

ASCT remains the standard of care for transplant-eligible MM patients. The depth of response pre-ASCT correlates with longterm outcome. ${ }^{(57)}$ Delivering the optimal novel agent-based induction regimen (bearing in mind the cost of these drugs) can be a challenge, as options for funding vary between institutions. We recommend that patients be included in high-quality randomised studies if they are eligible. With improved risk stratification and the availability of highly potent novel agents, the role of ASCT in $\mathrm{MM}$ is likely to evolve over the next few years.

\section{MANAGEMENT OF TRANSPLANT- INELIGIBLE PATIENTS}

\section{Patient selection}

Patients who are $>65$ years of age or have significant comorbidities are generally ineligible for high-dose therapy. Categorisation of their fitness to receive intensive treatment should be based on comorbidities and performance status, which may be assessed using a validated score (Table 1). ${ }^{(16)}$ The Charlson Comorbidity Index and Modified Barthel Index, which are used to assess activities of daily living, are recommended by the IMWG to determine fitness for therapy (Table 12). ${ }^{(72,73)}$

\section{Frontline management strategy for newly diagnosed transplant-ineligible patients}

The goal of therapy is to maximise treatment responses while minimising treatment-related toxicities. All patients should be considered for enrolment into clinical trials when they are available. The inclusion of a novel agent in frontline therapy for transplant-ineligible MM patients has been shown to result in more rapid disease control as well as improved survival. These regimens are also generally well tolerated. ${ }^{(74)}$ Outside of a clinical trial, we recommend PI-based induction, given its superior response rates and overall survival data. ${ }^{(75)}$ The FIRST trial showed that lenalidomide and dexamethasone (RD) is superior to melphalan, prednisolone and thalidomide (MPT) as a frontline regimen for transplant-ineligible MM patients. It is noteworthy that this effect was more apparent for continuous therapy with RD and that there has been no randomised study
Table 12. Fitness for therapy patient categorisation.

\begin{tabular}{lcc}
\hline $\begin{array}{l}\text { Patient } \\
\text { category }\end{array}$ & $\begin{array}{c}\text { Charlson Comorbidity } \\
\text { Index score }\end{array}$ & $\begin{array}{c}\text { Modified Barthel } \\
\text { Index score }\end{array}$ \\
\hline Fit & $0-3$ & $75-59$ \\
Intermediate* & $\geq 2$ with MBI score $<49$ & $49-74$ \\
Unfit & $\geq 4$ & $0-48$ \\
\hline
\end{tabular}

*Case-by-case decision on fitness required

Table 13. Frontline treatment options for transplant-ineligible multiple myeloma patients.

\begin{tabular}{|c|c|c|}
\hline $\begin{array}{l}\text { Patient } \\
\text { fitness } \\
\text { level }\end{array}$ & Treatment option & $\begin{array}{l}\text { Suggested } \\
\text { regimen }\end{array}$ \\
\hline Very fit & $\begin{array}{l}\text { Consider induction (e.g. VCD) } \\
\text { followed by reduced-intensity } \\
\text { autologous transplant }\end{array}$ & - \\
\hline \multirow[t]{2}{*}{ Fit } & Proteasome inhibitor-based & VMP; VCD; VD; VRD \\
\hline & Non-proteasome inhibitor-based & MPT; CTDa; TD; RD \\
\hline Unfit & $\begin{array}{l}\text { Tailored according to patient } \\
\text { with appropriate dose } \\
\text { attenuation }\end{array}$ & - \\
\hline
\end{tabular}

CTDa: cyclophosphamide, thalidomide and dexamethasone (attenuated); MPT: melphalan, prednisolone and thalidomide; RD: lenalidomide and dexamethasone; TD: thalidomide, dexamethasone; VCD: bortezomib, cyclophosphamide and dexamethasone; VD: bortezomib and dexamethasone; VMP: bortezomib, melphalan and prednisolone; VRD: bortezomib, lenalidomide and dexamethasone

Table 14. Comparison of response rates with the protocols described.

\begin{tabular}{lcccccc}
\hline Response & VCD & VMP & VD & CTD & MPT & TD \\
\hline CR (\%) & $10-39$ & 30 & $6-20$ & 22.5 & $10-15$ & $4-25$ \\
$\geq$ PR (\%) & $84-88$ & 70 & $65-85$ & 72.5 & $60-70$ & 63 \\
\hline
\end{tabular}

CR: complete remission; CTD: cyclophosphamide, thalidomide and dexamethasone; MPT: melphalan, prednisolone and thalidomide; PR: partial remission; TD: thalidomide and dexamethasone; VCD: bortezomib, cyclophosphamide and dexamethasone; VD: bortezomib and dexamethasone; VMP: bortezomib, melphalan and prednisolone

comparing RD to a PI-based regimen. ${ }^{(76)}$ However, RD should be considered a potential frontline option for transplant-ineligible MM patients. The VRD regimen was compared against RD for transplant-ineligible MM patients in a randomised study, which showed the superiority of VRD. ${ }^{(77)}$ Although this represents another potential treatment option, VRD has not been compared to other bortezomib-based combinations. Suggested treatment protocols are summarised and the regimens described in Table 13. A comparison of the efficacy of various treatments is also summarised in Table 14. Very fit patients aged $65-75$ years may be considered for reduced-intensity autologous transplant (e.g. melphalan $\left.100 \mathrm{mg} / \mathrm{m}^{2}\right){ }^{(45)}$

\section{Monitoring of response to therapy}

We recommend that $M$-protein quantification, immunoglobulin level, FBC, renal function and calcium levels should be monitored after each cycle. SFLC levels, instead of M-protein quantification, may be used for light chain myeloma. Once an M-protein plateau is reached, M-protein quantification may be performed every 2-3 months. Bone marrow studies should be used to confirm complete remission when applicable or to investigate unexplained cytopenia. ${ }^{(12)}$ 


\section{Duration of induction therapy}

We recommend treatment until at least a PR and m-band plateau is achieved. This is defined as three consecutive $\mathrm{m}$-band results, which qualify for at least a PR, and being stable with no new CRAB features. As a guide, 9-12 cycles of therapy is recommended if no maintenance is planned and 6-9 cycles if maintenance is planned. The decision to continue treatment should be balanced against toxicity. ${ }^{(78)}$

\section{Maintenance therapy}

Thalidomide and lenalidomide maintenance have been shown to prolong progression-free survival, but the overall survival benefit remains controversial. ${ }^{(69,79)}$ Thalidomide maintenance may be considered, but it should be limited to a one-year duration in view of the risk of neuropathy. ${ }^{(69)}$ The FIRST trial has demonstrated the efficacy and tolerability of continuous RD in transplant-ineligible patients. In this study, the continuous RD arm showed improved response rates, progression-free survival and overall survival at interim analysis as compared to MPT. ${ }^{(76)}$ Single-agent bortezomib maintenance has not been assessed in the transplant-ineligible population. Bortezomib and thalidomide (VT) or bortezomib and prednisolone (VP) maintenance following bortezomib, thalidomide and prednisolone (VTP) or bortezomib, melphalan and prednisolone (VMP) induction showed better response and progression-free survival as compared to the VMP regimen without maintenance, but there was no overall survival benefit. However, comparison of VP and VT in this study is difficult in view of the different induction regimens used. ${ }^{(80)}$ It is, therefore, not possible to recommend bortezomib maintenance at this point.

The achievement of an overall survival benefit through maintenance therapy may be difficult to demonstrate due to the availability of effective salvage treatment at relapse. ${ }^{(81)}$ There is emerging evidence to suggest the efficacy of the continuous use of $\mathrm{RD}$ rather than a fixed duration of an alkylator-based regime. ${ }^{(76)}$ As for other induction regimes, there is currently insufficient data to justify the routine use of maintenance therapy outside of clinical trials. A thorough discussion of the financial aspects and qualityof-life considerations should be undertaken with the patient when offering the option of maintenance therapy.

\section{Suggested protocols}

We suggest the following treatment protocols as options for transplant-ineligible patients with MM. The protocols are described in detail in the respective tables.

- Bortezomib, melphalan and prednisolone (VMP) $)^{(75,80)}$ (Table 15)

- Bortezomib, cyclophosphamide and dexamethasone $(\mathrm{VCD})^{(47,48)}$ (Table 16)

- $\quad$ Bortezomib and dexamethasone (VD) ${ }^{(82)}$ (Table 17)

- Cyclophosphamide, thalidomide and dexamethasone attenuated (CTDa) ${ }^{(54)}$ (Table 18)

- $\quad$ Melphalan, prednisolone and thalidomide (MPT) $)^{(83)}$ (Table 19)

- $\quad$ Thalidomide and dexamethasone (TD) ${ }^{(84)}$ (Table 20)

- Bortezomib, lenalidomide and dexamethasone (VRD) $(\text { Table } 9)^{(77)}$
Table 15. VMP (bortezomib, melphalan and prednisolone) protocol.

\begin{tabular}{lllc}
\hline Day & Drug & Route & Dose \\
\hline $1,8,15,22$ & Bortezomib & Subcutaneous & $1.3 \mathrm{mg} / \mathrm{m}^{2}$ \\
$1-4$ & Melphalan & Per os & $9 \mathrm{mg} / \mathrm{m}^{2} /$ day \\
$1-4$ & Prednisolone & Per os & $60 \mathrm{mg} / \mathrm{m}^{2} /$ day \\
\hline
\end{tabular}

Cycle length: 35 days.

Table 16. VCD (bortezomib, cyclophosphamide and dexamethasone) protocol, as modified from Reeder et al. ${ }^{(47)}$

\begin{tabular}{lllc}
\hline Day & Drug & Route & Dose \\
\hline $1,8,15,22$ & Bortezomib & Subcutaneous & $1.3 \mathrm{mg} / \mathrm{m}^{2}$ \\
$1,8,15,22$ & Cyclophosphamide & Per os & $300 \mathrm{mg} / \mathrm{m}^{2}$ \\
$1,2,8,9$, & Dexamethasone & Per os & $20 \mathrm{mg}$ \\
15,16, & & & \\
22,23 & & & \\
\hline
\end{tabular}

Cycle length: 28 days.

Table 17. VD (bortezomib and dexamethasone) protocol, as modified from Girnius et al. ${ }^{(82)}$

\begin{tabular}{lllc}
\hline Day & Route & Route & Dose \\
\hline $1,8,15,22$ & Drug & Subcutaneous & $1.3 \mathrm{mg} / \mathrm{m}^{2}$ \\
$1,2,8,9,15$, & Bortezomib & Per os & $20 \mathrm{mg}$ \\
$16,22,23$ & & & \\
\hline
\end{tabular}

Cycle length: 28 days.

Table 18. CTDa (cyclophosphamide, thalidomide and dexamethasone) attenuated protocol, as modified from Morgan et al. ${ }^{(54)}$

\begin{tabular}{lllc}
\hline Day & Drug & Route & Dose \\
\hline $1,8,15,22$ & Cyclophosphamide & Per os & $500 \mathrm{mg}$ \\
$1-28$ & Thalidomide & Per os & $100 \mathrm{mg}$ \\
$1-4$ and 15-18 & Dexamethasone* $^{\text {Dex }}$ & Per os & $20 \mathrm{mg}$ \\
\hline
\end{tabular}

Cycle length: 28 days. *In patients for whom 'pulsed' dexamethasone is considered unsuitable, dexamethasone $20 \mathrm{mg}$ on Days 1, 8, 15 and 22 can be considered.

Table 19. MPT (melphalan, prednisolone and thalidomide) protocol, as modified from Palumbo et al. ${ }^{(83)}$

\begin{tabular}{lllc}
\hline Day & Drug & Route & Dose \\
\hline $1-7$ & Melphalan & Per os & $4 \mathrm{mg} / \mathrm{m}^{2} /$ day \\
$1-7$ & Prednisolone & Per os & $40 \mathrm{mg} / \mathrm{m}^{2} /$ day \\
$1-28$ & Thalidomide & Per os & $50-100 \mathrm{mg} /$ day \\
\hline
\end{tabular}

Cycle length: 28 days.

Table 20. TD (thalidomide and dexamethasone) protocol.

\begin{tabular}{lllcl}
\hline Day & Drug & Route & Dose & Cycle \\
\hline $1-28$ & Thalidomide & Per os & $200 \mathrm{mg} /$ day & - \\
$1-4$ & Dexamethasone & Per os & $40 \mathrm{mg} /$ day & Odd \\
$1-4,15-18$ & Dexamethasone & Per os & $40 \mathrm{mg} /$ day & Even \\
\hline
\end{tabular}

Cycle length: 28 days.

Table 21. RD (lenalidomide and dexamethasone) protocol.

\begin{tabular}{lllc}
\hline Day & Drug & Route & Dose \\
\hline $1-21$ & Lenalidomide & Per os & $25 \mathrm{mg}$ per day \\
$1,8,15,22$ & Dexamethasone & Per os & $40 \mathrm{mg}$ per day \\
\hline
\end{tabular}

Cycle length: 28 days. 
Table 22. Dose adjustments in elderly patients with multiple myeloma, as adapted from Palumbo et al. ${ }^{(85)}$

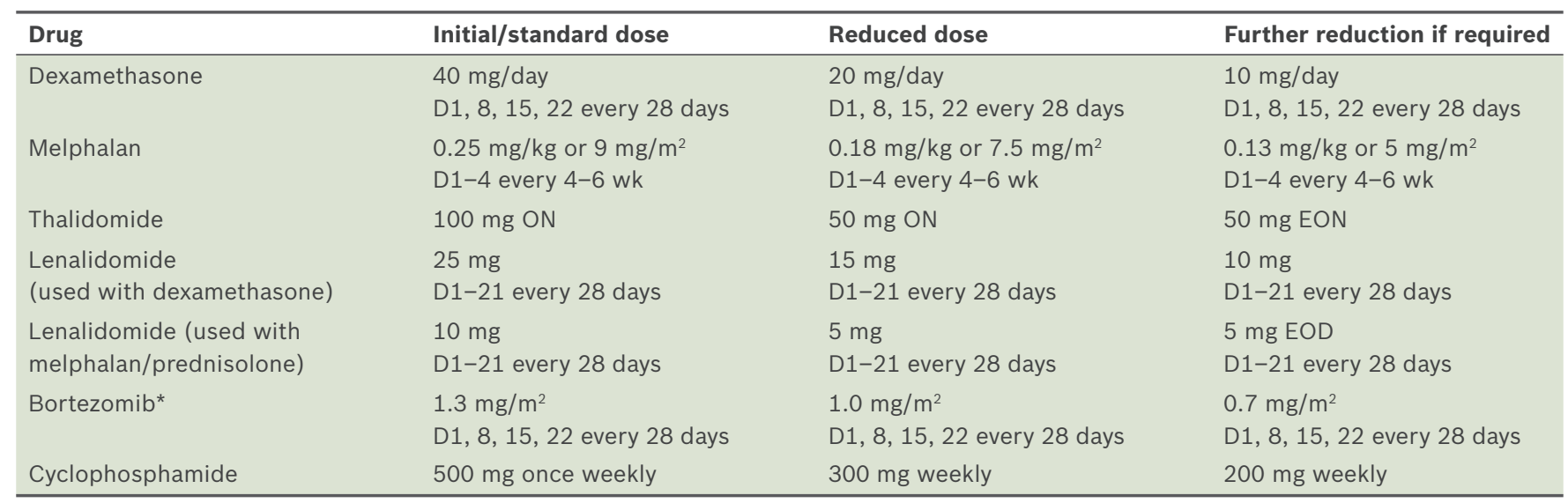

* To consider using bortezomib $1.3 \mathrm{mg} / \mathrm{m}^{2}$ twice weekly on Day (D) $1,4,8$ and 11 , every $3 \mathrm{wk}$, in selected patients with renal impairment or those who require a rapid reduction in paraprotein levels. EOD: every other day; EON: every other night; ON: every night

Table 23. Dose adjustment and toxicity of bortezomib (VELCADE ${ }^{\circledR}$ [bortezomib] injection package insert).

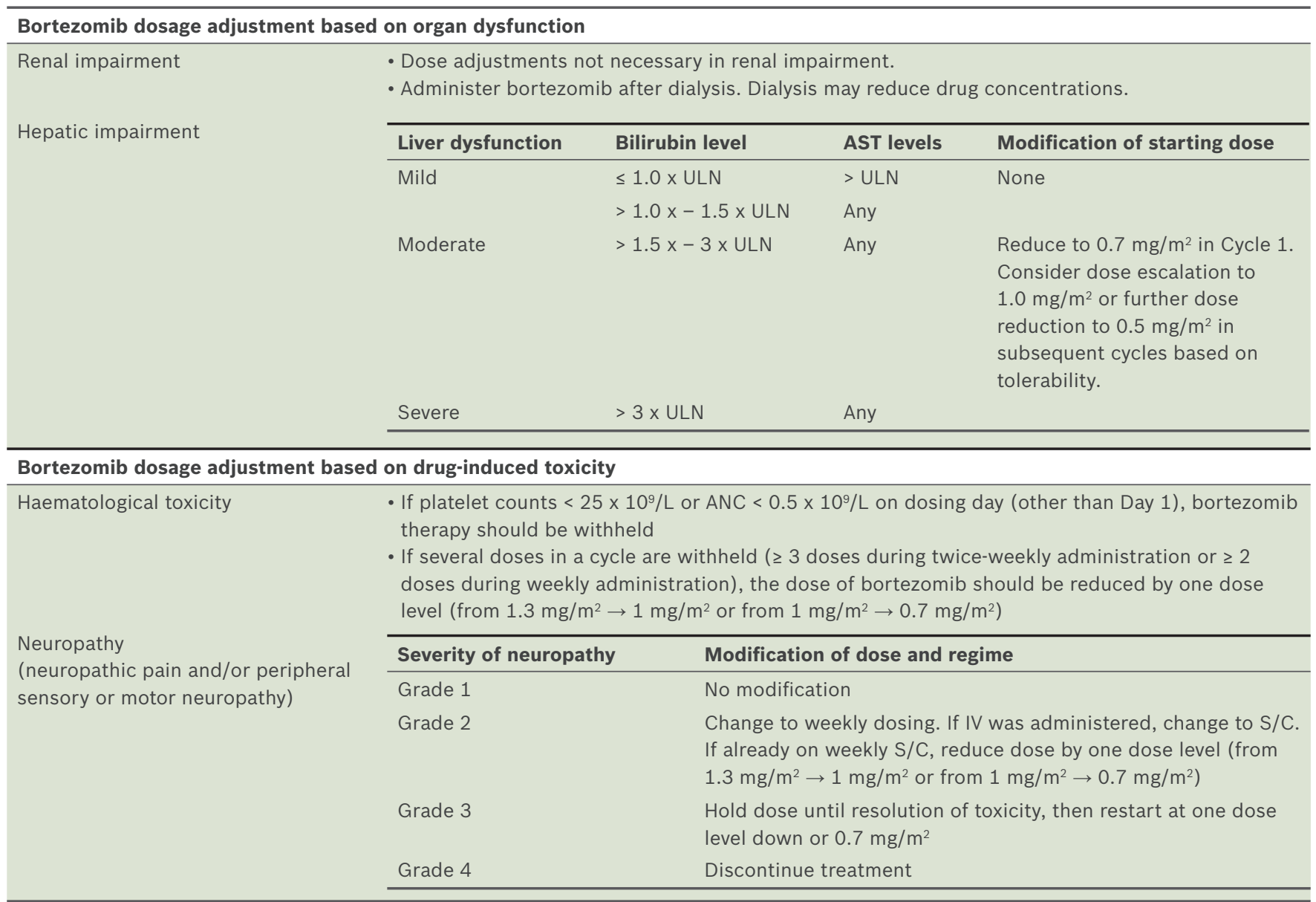

ANC: absolute neutrophil count; AST: aspartate aminotransferase test; IV: intravenous; S/C: subcutaneous; ULN: upper limit of normal

- $\quad$ Lenalidomide and dexamethasone (RD) ${ }^{(76)}$ (Table 21)

Dose adjustment guidelines, depending on patient fitness, are summarised in Table 22. ${ }^{(85)}$

\section{Conclusion}

The management of transplant-ineligible MM patients should be individualised. The approach should take into consideration the patient's disease burden, comorbidities and the likelihood of treatment-related toxicities. While one of the goals is to attain the best disease response with treatment, the treating physician should not neglect the goals of minimising adverse effects and providing adequate supportive care.

The introduction of novel agents - bortezomib, thalidomide and lenalidomide - has changed the treatment practices for transplant-ineligible MM. These treatment regimens are effective, with manageable toxicities. The armamentarium has since undergone exponential expansion with the advent of second-generation PIs (e.g. ixazomib and carfilzomib) 
Table 24. Dose adjustment and toxicity of melphalan [ALKERAN ${ }^{\mathrm{TM}}$ (melphalan) injection package insert].

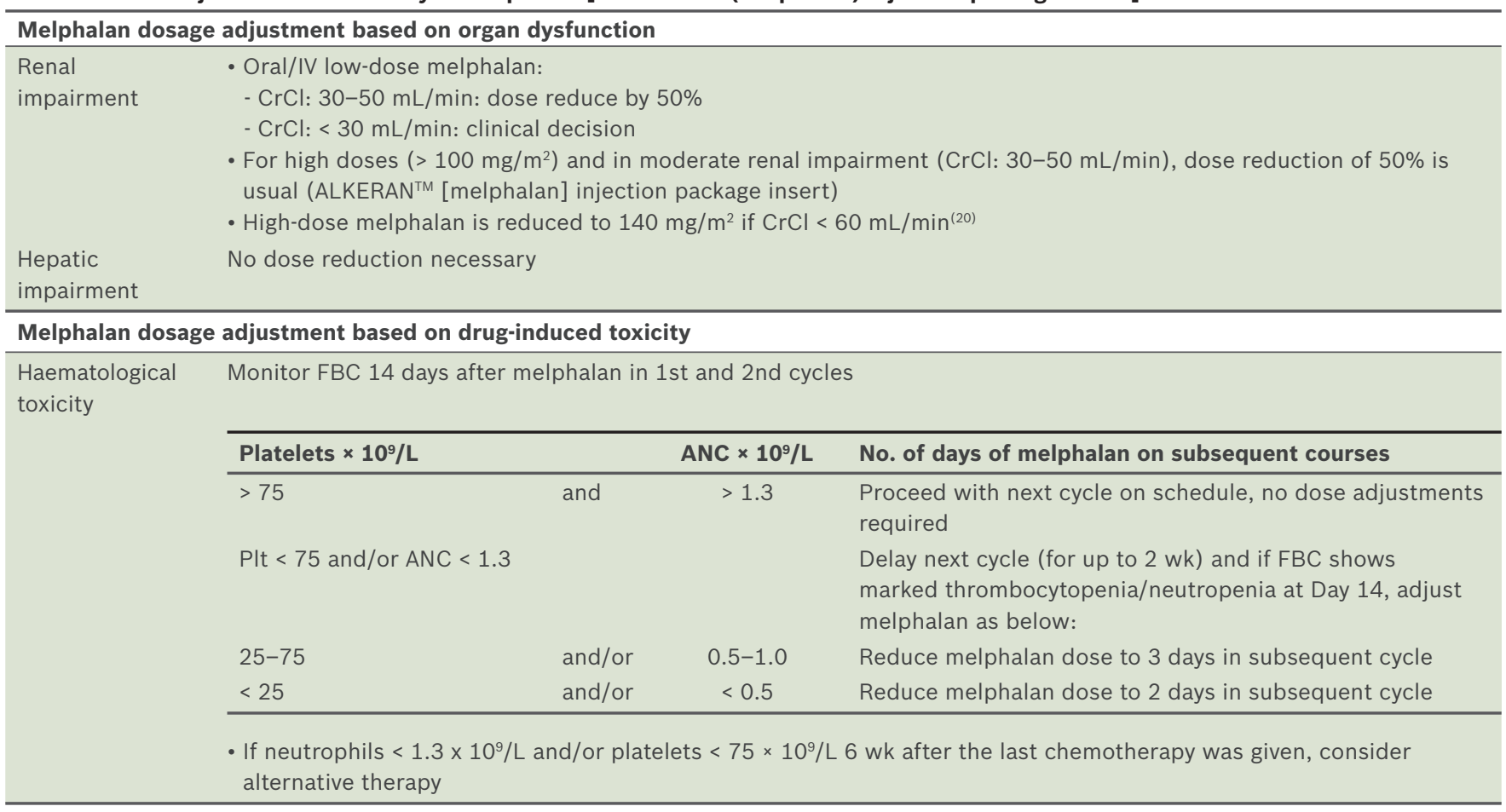

ANC: absolute neutrophil count; FBC: full blood count; $\mathrm{CrCl}$ : creatinine clearance; IV: intraveous; Plt: platelet count

Table 25. Dose adjustment and toxicity of thalidomide.

\begin{tabular}{|c|c|c|}
\hline \multicolumn{3}{|c|}{ Thalidomide dosage adjustment based on organ dysfunction } \\
\hline Renal impairment & \multicolumn{2}{|c|}{$\begin{array}{l}\text { - No dose adjustment required } \\
\text { - No supplemental dose required if on haemodialysis } \\
(91,92)\end{array}$} \\
\hline \multicolumn{3}{|c|}{ Management of drug-induced toxicities } \\
\hline \multirow[t]{6}{*}{ Peripheral neuropathy (PN) } & \multicolumn{2}{|c|}{$\begin{array}{l}\text { - Monitor for PN, especially in first few months of therapy } \\
\text { - Thalidomide-induced neuropathy can be irreversible, thus patient should be informed to stop treatment } \\
\text { if significant numbness or paraesthesia occurs }\end{array}$} \\
\hline & Severity of neuropathy & Modification of dose \\
\hline & Grade 1 & No modification \\
\hline & Grade 2 & $\begin{array}{l}\text { Reduce dose by } 50 \% \text { or hold therapy till resolution of toxicity, then restart at } \\
50 \% \text { of dose }\end{array}$ \\
\hline & Grade 3 & Stop till resolution of toxicity, restart at low dose when PN Grade 1 \\
\hline & Grade 4 & Discontinue treatment \\
\hline Sedation & \multicolumn{2}{|c|}{$\begin{array}{l}\text { - Decreases with continued administration of constant dose } \\
\text { - 'Hangover effect' can by minimised by administering in the evening, approximately } 3-4 \mathrm{hr} \text { before bedtime }\end{array}$} \\
\hline Constipation & \multicolumn{2}{|c|}{$\begin{array}{l}\text { - Significant at higher doses } \\
\text { - Can be overcome with extra dietary fibre and laxatives }\end{array}$} \\
\hline Hypothyroidism & \multicolumn{2}{|c|}{ - Monitor thyroid function and manage hypothyroidism accordingly } \\
\hline
\end{tabular}

and immunomodulators (e.g. pomalidomide), as well as the introduction of immunotherapy (e.g. daratumumab and checkpoint inhibitors). ${ }^{(86-90)}$ However, while such potent drugs may be available, the physician is tasked to justify the added benefits of administering these treatments by weighing them against the financial burdens they may bring.

\section{DRUG TOXICITY AND DOSE ADJUSTMENTS}

This section provides guidance on the dosages and administration of drugs commonly used in treating MM. Recommendations for dose adjustments in renal and hepatic impairment, as well as information on common toxicities, are also provided. The source of this information is the manufacturers' package insert and recent publications in the field. We recommend that an oncology-trained pharmacist be responsible for dispensing these agents.

\section{Bortezomib}

Bortezomib is currently the first choice for standard PI-based induction. For Cycle 1, FBC should be assessed 24 hours prior to the first and third dose of bortezomib. For subsequent cycles, FBC should be assessed at least twice per cycle. More 
Table 26. Dose adjustment and toxicity of cyclophosphamide (ENDOXAN ${ }^{\circledR}$ [cyclophosphamide] package insert).

\begin{tabular}{|c|c|c|c|}
\hline \multicolumn{4}{|c|}{ Cyclophosphamide dosage adjustment based on organ dysfunction } \\
\hline Renal impairment & \multicolumn{3}{|c|}{$\begin{array}{l}\text { - } \mathrm{CrCl} \geq 10 \mathrm{~mL} / \mathrm{min} \text { : no dose adjustment required } \\
\text { - } \mathrm{CrCl}<10 \mathrm{~mL} / \mathrm{min} \text { : administer } 50 \% \text { (package insert) to } 75 \% \text { (up to date) of normal dose } \\
\text { - Cyclophosphamide is moderately dialysable } \\
\text { - Haemodialysis: administer } 50 \% \text { of normal dose, post-haemodialysis } \\
\text { - Continuous ambulatory peritoneal dialysis: administer } 75 \% \text { of normal dose } \\
\text { - Continuous renal replacement therapy: administer } 100 \% \text { of normal dose }\end{array}$} \\
\hline Hepatic impairment & \multicolumn{3}{|c|}{$\begin{array}{l}\text { - Serum bilirubin } 3.1-5 \mathrm{mg} / \mathrm{dL} \text { or transaminases }>3 \text { times ULN: administer } 75 \% \text { of dose } \\
\text { - Serum bilirubin }>5 \mathrm{mg} / \mathrm{mL} \text { : avoid use } \\
\text { - Severe hepatic impairment may reduce conversion of cyclophosphamide to its active metabolite, potentially } \\
\text { reducing efficacy of treatment }\end{array}$} \\
\hline \multicolumn{4}{|c|}{ Cyclophosphamide dosage adjustment based on drug-induced toxicity } \\
\hline \multirow[t]{5}{*}{ Haematological toxicity } & \multicolumn{3}{|c|}{ - Recommendations for dose adjustment in myelosuppression (mainly for cyclophosphamide as monotherapy) } \\
\hline & Platelets $\times 10^{9} / \mathrm{L}$ & WBC $\times 10^{\circ} / \mathrm{L}$ & No. of days of melphalan on subsequent courses \\
\hline & $>100$ & $>4.0$ & $100 \%$ of normal dose \\
\hline & $50-100$ & $2.5-4.0$ & $50 \%$ of normal dose \\
\hline & $<50$ & $<2.5$ & Hold till counts recover \\
\hline
\end{tabular}

CrCl: creatinine clearance; ULN: upper limit of normal; WBC: white blood cell

Table 27. Dose adjustment and toxicity of lenalidomide.

Lenalidomide dosage adjustment based on organ dysfunction

Renal impairment

- Mild renal impairment: no dose adjustment required

- Recommended starting doses in moderate or severe impairment or ESRF are as follows:

\begin{tabular}{lll}
\hline $\begin{array}{l}\text { Renal } \\
\text { impairment }\end{array}$ & CrCl (mL/min) & $\begin{array}{l}\text { Dose adjustment (Days 1-21 of a 28-day } \\
\text { cycle) }\end{array}$ \\
\hline $\begin{array}{l}\text { Moderate } \\
\text { Severe }\end{array}$ & $\begin{array}{l}30-50 \\
<30, \text { not requiring } \\
\text { dialysis } \\
\text { ESRF }\end{array}$ & $\begin{array}{l}15 \mathrm{mg} \text { every other day }{ }^{+} \\
\text {dialysis }\end{array}$ \\
\end{tabular}

*Dose may be escalated to $15 \mathrm{mg}$ once daily after 2 cycles if patient is not responding to treatment and is tolerating the treatment. 'Dose may be escalated to $10 \mathrm{mg}$ once daily if the patient is tolerating the treatment

Hepatic impairment

- No recommendations for dosage adjustments in manufacturer's labelling

REVLIMID ${ }^{\circledR}$ (lenalidomide)

package insert

\begin{tabular}{ll}
\hline Starting dose (Day 1-21 every 28 days) & $\mathbf{2 5} \mathbf{~ m g ~ O D ~}$ \\
\hline Dose level - & $15 \mathrm{mg}$ OD \\
Dose level - 2 & $10 \mathrm{mg}$ OD \\
Dose level -3 & $5 \mathrm{mg} \mathrm{OD}$ \\
\hline
\end{tabular}

\begin{tabular}{|c|c|c|}
\hline \multicolumn{3}{|c|}{ Lenalidomide dosage adjustment based on drug-induced toxicity } \\
\hline \multirow{11}{*}{ Neutropenia } & When platelet count & Recommended course \\
\hline & First falls to $<30 \times 10^{9} / \mathrm{L}$ & Interrupt treatment \\
\hline & Returns to $\geq 30 \times 10^{9} / \mathrm{L}$ & Resume at dose level -1 \\
\hline & For each subsequent drop $<30 \times 10^{9} / \mathrm{L}$ & Interrupt treatment \\
\hline & Returns to $\geq 30 \times 10^{9} / \mathrm{L}$ & $\begin{array}{l}\text { Resume at next dose level } \\
\text { lower }\end{array}$ \\
\hline & When neutrophil count & Recommended course \\
\hline & First falls to $<1.0 \times 10^{9} / \mathrm{L}$ & Interrupt treatment \\
\hline & $\begin{array}{l}\text { Returns to } \geq 1.0 \times 10^{9} / \mathrm{L} \text {, when neutropenia is the only } \\
\text { observed toxicity }\end{array}$ & Resume at starting dose \\
\hline & $\begin{array}{l}\text { Returns to } \geq 1.0 \times 10^{9} / \mathrm{L} \text {, when dose-dependent } \\
\text { haematological toxicities other than neutropenia are } \\
\text { observed }\end{array}$ & Resume at dose level -1 \\
\hline & For each subsequent drop $<1.0 \times 10^{9} / \mathrm{L}$ & Interrupt treatment \\
\hline & Returns to $\geq 1.0 \times 10^{9} / \mathrm{L}$ & $\begin{array}{l}\text { Resume at next dose level } \\
\text { lower }\end{array}$ \\
\hline
\end{tabular}

$\mathrm{CrCl}$ : creatinine clearance; ESRF: end-stage renal failure; OD: once daily 
Table 28. Dose adjustment and toxicity of carfilzomib.

\begin{tabular}{|c|c|}
\hline \multicolumn{2}{|c|}{ Carfilzomib dosage adjustment based on drug-induced toxicity } \\
\hline $\begin{array}{l}\text { Haematological toxicity } \\
\text { (Grade } 3 / 4 \text { neutropenia; } \\
\text { Grade } 4 \text { thrombocytopenia) }\end{array}$ & $\begin{array}{l}\text { - Withhold dose } \\
\text { - Resume at same dose level if counts recover fully before next scheduled dose } \\
\text { - If recover to Grade } 2 \text { neutropenia or Grade } 3 \text { thrombocytopenia, reduce dose by one dose } \\
\text { level (from } 27 \mathrm{mg} / \mathrm{m}^{2} \rightarrow 20 \mathrm{mg} / \mathrm{m}^{2} \text {, or from } 20 \mathrm{mg} / \mathrm{m}^{2} \rightarrow 15 \mathrm{mg} / \mathrm{m}^{2} \text { ) } \\
\text { - If tolerated, may escalate back to previous dose at physician's discretion }\end{array}$ \\
\hline $\begin{array}{l}\text { Cardiac toxicity } \\
\text { (Grade } 3 \text { or } 4 \text {, new onset or } \\
\text { worsening of: congestive heart } \\
\text { failure; decreased left ventricular } \\
\text { function; myocardial ischaemia) }\end{array}$ & $\begin{array}{l}\text { - Withhold dose until resolved or returned to baseline } \\
\text { - After resolution, consider if restarting at a reduced dose is appropriate } \\
\text { (from } 27 \mathrm{mg} / \mathrm{m}^{2} \rightarrow 20 \mathrm{mg} / \mathrm{m}^{2} \text {, or from } 20 \mathrm{mg} / \mathrm{m}^{2} \rightarrow 15 \mathrm{mg} / \mathrm{m}^{2} \text { ) } \\
\text { - If tolerated, may escalate back to previous dose at physician's discretion }\end{array}$ \\
\hline Pulmonary hypertension & $\begin{array}{l}\text { - Withhold dose until resolved or returned to baseline } \\
\text { - Restart at dose used prior to event or reduced dose level (from } 27 \mathrm{mg} / \mathrm{m}^{2} \rightarrow 20 \mathrm{mg} / \mathrm{m}^{2} \text {, } \\
\text { or from } 20 \mathrm{mg} / \mathrm{m}^{2} \rightarrow 15 \mathrm{mg} / \mathrm{m}^{2} \text { ), at physician's discretion } \\
\text { - If tolerated, may escalate back to previous dose at physician's discretion }\end{array}$ \\
\hline $\begin{array}{l}\text { Hepatic toxicity } \\
\text { (Grade } 3 \text { or } 4 \text { elevation of } \\
\text { transaminases, bilirubin or } \\
\text { other liver abnormalities) }\end{array}$ & $\begin{array}{l}\text { - Withhold dose until resolved or returned to baseline } \\
\text { - After resolution, consider if restarting at a reduced dose is appropriate (from } 27 \mathrm{mg} / \mathrm{m}^{2} \rightarrow 20 \mathrm{mg} / \mathrm{m}^{2} \text {, } \\
\text { or from } 20 \mathrm{mg} / \mathrm{m}^{2} \rightarrow 15 \mathrm{mg} / \mathrm{m}^{2} \text { ), with close monitoring of liver function } \\
\text { - If tolerated, may escalate back to previous dose at physician's discretion }\end{array}$ \\
\hline $\begin{array}{l}\text { Renal toxicity } \\
\text { (Serum creatinine } \geq 2 \times \text { baseline) }\end{array}$ & $\begin{array}{l}\text { - Withhold dose until recovered to Grade } 1 \text { or returned to baseline; monitor renal function } \\
\text { - If attributable to drug, restart at next scheduled treatment at reduced dose level } \\
\text { (from } 27 \mathrm{mg} / \mathrm{m}^{2} \rightarrow 20 \mathrm{mg} / \mathrm{m}^{2} \text {, or from } 20 \mathrm{mg} / \mathrm{m}^{2} \rightarrow 15 \mathrm{mg} / \mathrm{m}^{2} \text { ), at physician's discretion } \\
\text { - If not attributable to drug, restart at the dose used prior to event } \\
\text { - If tolerated, may escalate back to previous dose at physician's discretion }\end{array}$ \\
\hline $\begin{array}{l}\text { Peripheral neuropathy } \\
\text { (Grade } 3 \text { or } 4 \text { ) }\end{array}$ & $\begin{array}{l}\text { - Withhold dose until resolved or returned to baseline } \\
\text { - Restart at dose used prior to event or reduced dose level (from } 27 \mathrm{mg} / \mathrm{m}^{2} \rightarrow 20 \mathrm{mg} / \mathrm{m}^{2} \text {, } \\
\text { or from } 20 \mathrm{mg} / \mathrm{m}^{2} \rightarrow 15 \mathrm{mg} / \mathrm{m}^{2} \text { ), at physician's discretion } \\
\text { - If tolerated, may escalate back to previous dose at physician's discretion }\end{array}$ \\
\hline
\end{tabular}

regular monitoring may be considered on a case-by-case basis, depending on the severity of cytopenia at the beginning of the cycle and concurrent cytotoxic therapy. Prior to initiating a new cycle of therapy (Table 23), these conditions should be met: platelet count $>70 \times 10^{9} / \mathrm{L}$; absolute neutrophil count $>$ $1.0 \times 10^{9} / \mathrm{L}$; non-haematological toxicities resolved to Grade 1 or baseline; and renal and liver function checked before each cycle.

\section{Melphalan}

Melphalan is indicated as part of the VMP and MPT protocols, as well as in conditioning for SCT. Significant haematologic and gastrointestinal toxicities are well known. Dose adjustment for renal impairment is recommended (Table 24).

\section{Thalidomide}

Thalidomide is an important component of multiple treatment protocols in both transplant-eligible and -ineligible patients. Peripheral neuropathy, constipation, sedation and hypothyroidism are significant toxicities (Table 25).

\section{Cyclophosphamide}

Cyclophosphamide is indicated in the VCD and CTD regimens. The main toxicity is haematologic, and adjustment is required for renal and hepatic impairment (Table 26).

\section{Lenalidomide}

The recommended starting dose of lenalidomide is $25 \mathrm{mg}$ once daily on Days 1-21 of a 28-day cycle. The recommended dose of dexamethasone is $40 \mathrm{mg}$ orally once daily on Days 1, 8, 15 and 22. ${ }^{(55)}$ Prior to initiating a new cycle of therapy (Table 27), these conditions should be met: platelet count $>30 \times 10^{9} / \mathrm{L}$; and absolute neutrophil count $>1.0 \times 10^{9} / \mathrm{L}$.

\section{Carfilzomib}

Carfilzomib (exemption supply, i.e. check with institutional pharmacy for cost and forms for application of drug) is administered as an intravenous injection over 2-10 minutes, on two consecutive days each week for three weeks (Days 1, 2, 8, 9,15 and 16), followed by a 12-day rest period every 28 days. In Cycle 1, carfilzomib is given at a dose of $20 \mathrm{mg} / \mathrm{m}^{2}$. If tolerated, the dose should be escalated to $27 \mathrm{mg} / \mathrm{m}^{2}$ in subsequent cycles. Prior to each dose in Cycle 1, administer $250-500 \mathrm{~mL}$ of intravenous normal saline and an additional $250-500 \mathrm{~mL}$ of intravenous fluids as needed, following carfilzomib administration. Continued intravenous hydration is required in subsequent cycles to ensure adequate hydration while preventing fluid overload.

Premedication with oral or intravenous dexamethasone $4 \mathrm{mg}$ prior to all doses of carfilzomib in Cycle 1, and prior to all doses during the first cycle of dose escalation to $27 \mathrm{mg} / \mathrm{m}^{2}$, is required to reduce the incidence and severity of infusion-related 
reactions. Dexamethasone premedication should be reinstated if these symptoms develop or reappear during subsequent cycles (Table 28).

\section{CONCLUSION}

The details regarding dose adjustments for each drug are described in the aforementioned tables. We suggest that prescribing physicians refer to the relevant drug package insert for a more comprehensive review of toxicity and dose adjustments. We reiterate the importance of good communication and collaboration with the haemato-oncology pharmacy team when using these agents.

\section{REFERENCES}

1. International Myeloma Working Group. Criteria for the classification of monoclonal gammopathies, multiple myeloma and related disorders: a report of the International Myeloma Working Group. Br J Haematol 2003; 121:749-57.

2. Kyle RA, Durie BG, Rajkumar SV, et al; International Myeloma Working Group. Monoclonal gammopathy of undetermined significance (MGUS) and smoldering (asymptomatic) multiple myeloma: IMWG consensus perspectives risk factors for progression and guidelines for monitoring and management. Leukemia 2010; 24:1121-7.

3. Moreau P, Attal M, Facon T. Frontline therapy of multiple myeloma. Blood 2015; 125:3076-84.

4. Mateos MV, Hernández MT, Giraldo $\mathrm{P}$, et al. Lenalidomide plus dexamethasone for high-risk smoldering multiple myeloma. New Engl J Med 2013; 369:438-47.

5. Dispenzieri A, Stewart AK, Chanan-Khan A, et al. Smoldering multiple myeloma requiring treatment: time for a new definition? Blood 2013; 122:4172-81.

6. Rajkumar SV, Dimopoulos MA, Palumbo A, et al. International Myeloma Working Group updated criteria for the diagnosis of multiple myeloma. Lancet Oncol 2014; 15:e538-48.

7. Dispenzieri A, Kyle R, Merlini G, et al; International Myeloma Working Group. International Myeloma Working Group guidelines for serum-free light chain analysis in multiple myeloma and related disorders. Leukemia 2009; 23:215-24.

8. Rajkumar SV, Harousseau JL, Durie B, et al; International Myeloma Workshop Consensus Panel 1. Consensus recommendations for the uniform reporting of clinical trials: report of the International Myeloma Workshop Consensus Panel 1. Blood 2011; 117:4691-5.

9. Pianko MJ, Terpos E, Roodman GD, et al. Whole-body low-dose computed tomography and advanced imaging techniques for multiple myeloma bone disease. Clin Cancer Res 2014; 20:5888-97.

10. Chng WJ, Dispenzieri A, Chim CS, et al; International Myeloma Working Group. IMWG consensus on risk stratification in multiple myeloma. Leukemia 2014; 28:269-77.

11. Palumbo A, Avet-Loiseau H, Oliva S, et al. Revised International Staging System for Multiple Myeloma: A Report From International Myeloma Working Group. J Clin Oncol 2015; 33:2863-9.

12. Pratt $G$, Jenner $M$, Owen $R$, et al. Updates to the guidelines for the diagnosis and management of multiple myeloma. Br J Haematol 2014; 167:131-3.

13. Tan D, Ong KH, Koh LP, et al. The impact of frontline risk-adapted strategy on the overall survival of patients with newly diagnosed multiple myeloma: an analysis of the Singapore multiple myeloma study group. Eur J Haematol 2012; 89:136-44.

14. Kyle RA, Gertz MA, Witzig TE, et al. Review of 1027 patients with newly diagnosed multiple myeloma. Mayo Clin Proc 2003; 78:21-33.

15. Snowden JA, Ahmedzai SH, Ashcroft J, et al; Haemato-oncology Task Force of British Committee for Standards in Haematology and UK Myeloma Forum. Guidelines for supportive care in multiple myeloma 2011. Br J Haematol 2011; 154:76-103.

16. Palumbo A, Rajkumar SV, San Miguel JF, et al. International Myeloma Working Group consensus statement for the management, treatment, and supportive care of patients with myeloma not eligible for standard autologous stem-cell transplantation. J Clin Oncol 2014; 32:587-600.

17. Palumbo A, Anderson K. Multiple myeloma. New Engl J Med 2011; 364:1046-60.

18. Major P, Lortholary A, Hon J, et al. Zoledronic acid is superior to pamidronate in the treatment of hypercalcemia of malignancy: a pooled analysis of two randomized, controlled clinical trials. J Clin Oncol 2001; 19:558-67.

19. Clark AD, Shetty A, Soutar R. Renal failure and multiple myeloma: pathogenesis and treatment of renal failure and management of underlying myeloma. Blood Rev 1999; 13:79-90.

20. Dimopoulos MA, Terpos E, Chanan-Khan A, et al. Renal impairment in patients with multiple myeloma: a consensus statement on behalf of the International Myeloma Working Group. J Clin Oncol 2010; 28:4976-84.

21. Yu X, Gan L, Wang Z, Dong B, Chen X. Chemotherapy with or without plasmapheresis in acute renal failure due to multiple myeloma: a metaanalysis. Int J Clin Pharmacol Ther 2015; 53:391-7.

22. Zannetti BA, Zamagni E, Santostefano M, et al. Bortezomib-based therapy combined with high cut-off hemodialysis is highly effective in newly diagnosed multiple myeloma patients with severe renal impairment. Am J Hematol 2015; 90:647-52.

23. Birgegård G, Gascón $\mathrm{P}$, Ludwig $\mathrm{H}$. Evaluation of anaemia in patients with multiple myeloma and lymphoma: findings of the European CANCER ANAEMIA SURVEY. Eur J Haematol 2006; 77:378-86.

24. Littlewood T, Mandelli F. The effects of anemia in hematologic malignancies: more than a symptom. Semin Oncol 2002; 29(3 Suppl 8):40-4.

25. Wu JS, Wong R, Johnston M, Bezjak A, Whelan T; Cancer Care Ontario Practice Guidelines Initiative Supportive Care Group. Meta-analysis of dose-fractionation radiotherapy trials for the palliation of painful bone metastases. Int J Radiat Oncol Biol Phys 2003; 55:594-605.

26. Prasad D, Schiff D. Malignant spinal-cord compression. Lancet Oncol 2005; 6:15-24.

27. Morgan GJ, Davies FE, Gregory WM, et al; National Cancer Research Institute Haematological Oncology Clinical Study Group. First-line treatment with zoledronic acid as compared with clodronic acid in multiple myeloma (MRC Myeloma IX): a randomised controlled trial. Lancet 2010; 376:1989-99.

28. Terpos E, Berenson J, Raje N, Roodman GD. Management of bone disease in multiple myeloma. Expert Rev Hematol 2014; 7:113-25.

29. Abe M, Miki H, Nakamura S. [Management of bone disease in myeloma patients: zoledronic acid or denosumab?]. Rinsho Ketsueki 2015; 56:9971004. Japanese.

30. Lacy MQ, Dispenzieri A, Gertz MA, et al. Mayo clinic consensus statement for the use of bisphosphonates in multiple myeloma. Mayo Clin Proc 2006; 81:1047-53.

31. Vickrey E, Allen S, Mehta J, Singhal S. Acyclovir to prevent reactivation of varicella zoster virus (herpes zoster) in multiple myeloma patients receiving bortezomib therapy. Cancer 2009; 115:229-32.

32. Anevlavis S, Kaltsas K, Bouros D. Prophylaxis for Pneumocystis Pneumonia (PCP) in non-HIV infected patients. Pneumon 2012; 25:348-50.

33. Chapel HM, Lee M, Hargreaves R, Pamphilon DH, Prentice AG. Randomised trial of intravenous immunoglobulin as prophylaxis against infection in plateau-phase multiple myeloma. The UK Group for Immunoglobulin Replacement Therapy in Multiple Myeloma. Lancet 1994; 343:1059-63.

34. Watson HG, Keeling DM, Laffan M, Tait RC, Makris M; British Committee for Standards in Haematology. Guideline on aspects of cancer-related venous thrombosis. Br J Haematol 2015; 170:640-8.

35. Palumbo A, Rajkumar SV, Dimopoulos MA, et al; International Working Myeloma Group. Prevention of thalidomide- and lenalidomide-associated thrombosis in myeloma. Leukemia 2008; 22:414-23.

36. Zangari M, Barlogie B, Anaissie E, et al. Deep vein thrombosis in patients with multiple myeloma treated with thalidomide and chemotherapy: effects of prophylactic and therapeutic anticoagulation. Br J Haematol 2004; 126:715-21.

37. Carrier M, Le Gal G, Tay J, Wu C, Lee AY. Rates of venous thromboembolism in multiple myeloma patients undergoing immunomodulatory therapy with thalidomide or lenalidomide: a systematic review and meta-analysis. J Thromb Haemost 2011; 9:653-63.

38. Koh Y, Bang SM, Lee JH, et al; Korean Multiple Myeloma Working Party. Low incidence of clinically apparent thromboembolism in Korean patients with multiple myeloma treated with thalidomide. Ann Hematol 2010; 89:201-6.

39. Hou J, Du X, Jin J, et al. A multicenter, open-label, phase 2 study of lenalidomide plus low-dose dexamethasone in Chinese patients with relapsed/refractory multiple myeloma: the MM-021 trial. J Hematol Oncol 2013; 6:41.

40. Cavo M, Rajkumar SV, Palumbo A, et al; International Myeloma Working Group. International Myeloma Working Group consensus approach to the 
treatment of multiple myeloma patients who are candidates for autologous stem cell transplantation. Blood 2011; 117:6063-73.

41. Child JA, Morgan GJ, Davies FE, et al. High-dose chemotherapy with hematopoietic stem-cell rescue for multiple myeloma. New Engl J Med 2003; 348:1875-83.

42. Sonneveld P, Schmidt-Wolf IG, van der Holt B, et al. Bortezomib induction and maintenance treatment in patients with newly diagnosed multiple myeloma: results of the randomized phase III HOVON-65/GMMG-HD4 trial. J Clin Oncol 2012; 30:2946-55.

43. Attal M, Harousseau JL, Stoppa AM, et al. A prospective, randomized trial of autologous bone marrow transplantation and chemotherapy in multiple myeloma. Intergroupe Français du Myélome. New Engl J Med 1996; 335:91-7.

44. Kumar SK, Dingli D, Lacy MQ, et al. Autologous stem cell transplantation in patients of 70 years and older with multiple myeloma: Results from a matched pair analysis. Am J Hematol 2008; 83:614-7.

45. Palumbo A, Bringhen S, Bertola A, et al. Multiple myeloma: comparison of two dose-intensive melphalan regimens (100 vs 200 mg/m(2)). Leukemia 2004; 18:133-8.

46. Cavo M, Tacchetti P, Patriarca F, et al. Bortezomib with thalidomide plus dexamethasone compared with thalidomide plus dexamethasone as induction therapy before, and consolidation therapy after, double autologous stem-cell transplantation in newly diagnosed multiple myeloma: a randomised phase 3 study. Lancet 2010; 376:2075-85.

47. Reeder CB, Reece DE, Kukreti V, et al. Once- versus twice-weekly bortezomib induction therapy with CyBorD in newly diagnosed multiple myeloma. Blood 2010; 115:3416-7.

48. Ong SY, Ng HY, Surendran S, et al. Subcutaneous bortezomib combined with weekly cyclophosphamide and dexamethasone is an efficient and well tolerated regime in newly diagnosed multiple myeloma. $\mathrm{Br} \mathrm{J}$ Haematol 2015; 169:754-6.

49. Sonneveld P, Goldschmidt H, Rosiñol L, et al. Bortezomib-based versus nonbortezomib-based induction treatment before autologous stem-cell transplantation in patients with previously untreated multiple myeloma: a meta-analysis of phase III randomized, controlled trials. J Clin Oncol 2013; 31:3279-87.

50. Leiba M, Kedmi M, Duek A, et al. Bortezomib-cyclophosphamidedexamethasone (VCD) versus bortezomib-thalidomide-dexamethasone (VTD) -based regimens as induction therapies in newly diagnosed transplant eligible patients with multiple myeloma: a meta-analysis. $\mathrm{Br}$ J Haematol 2014; 166:702-10.

51. Moreau P, Hulin C, Macro M, et al. 393 Bortezomib, Thalidomide and Dexamethasone (VTD) Is Superior to Bortezomib, Cyclophosphamide and Dexamethasone (VCD) Prior to Autologous Stem Cell Transplantation for Patients with De Novo Multiple Myeloma. Results of the Prospective IFM 2013-04 Trial (Oral and Poster Abstracts). American Society of Hematology. 57th Annual Meeting \& Exposition. Orlando, FL: December 6, 2015

52. Kumar S, Flinn I, Richardson PG, et al. Randomized, multicenter, phase 2 study (EVOLUTION) of combinations of bortezomib, dexamethasone, cyclophosphamide, and lenalidomide in previously untreated multiple myeloma. Blood 2012; 119:4375-82.

53. Richardson PG, Weller E, Lonial S, et al. Lenalidomide, bortezomib, and dexamethasone combination therapy in patients with newly diagnosed multiple myeloma. Blood 2010; 116:679-86.

54. Morgan GJ, Davies FE, Gregory WM, et al; National Cancer Research Institute Haematological Oncology Studies Group. Cyclophosphamide, thalidomide, and dexamethasone as induction therapy for newly diagnosed multiple myeloma patients destined for autologous stem-cell transplantation: MRC Myeloma IX randomized trial results. Haematologica 2012; 97:442-50.

55. Rajkumar SV, Jacobus S, Callander NS, et al; Eastern Cooperative Oncology Group. Lenalidomide plus high-dose dexamethasone versus lenalidomide plus low-dose dexamethasone as initial therapy for newly diagnosed multiple myeloma: an open-label randomised controlled trial. Lancet Oncol 2010; 11:29-37.

56. Rajkumar SV, Blood E, Vesole D, Fonseca R, Greipp PR; Eastern Cooperative Oncology Group. Phase III clinical trial of thalidomide plus dexamethasone compared with dexamethasone alone in newly diagnosed multiple myeloma: a clinical trial coordinated by the Eastern Cooperative Oncology Group. J Clin Oncol 2006; 24:431-6.

57. Lahuerta JJ, Mateos MV, Martínez-López J, et al. Influence of pre- and post-transplantation responses on outcome of patients with multiple myeloma: sequential improvement of response and achievement of complete response are associated with longer survival. J Clin Oncol 2008; 26:5775-82.
58. Tan D, Lao Z, Loh Y, et al. Attainment of at least a very good partial response after induction treatment is an important surrogate of longer survival for multiple myeloma. Bone Marrow Transplant 2010; 45:1625-30.

59. Hamadani M, Kochuparambil ST, Osman S, et al. Intermediate-dose versus low-dose cyclophosphamide and granulocyte colony-stimulating factor for peripheral blood stem cell mobilization in patients with multiple myeloma treated with novel induction therapies. Biol Blood Marrow Transplant 2012; 18:1128-35.

60. Annunziata M, Celentano M, Pocali B, et al. Vinorelbine plus intermediate dose cyclophosphamide is an effective and safe regimen for the mobilization of peripheral blood stem cells in patients with multiple myeloma. Ann Hematol 2006; 85:394-9.

61. Pérez-Simón JA, Martín A, Caballero D, et al. Clinical significance of CD34+ cell dose in long-term engraftment following autologous peripheral blood stem cell transplantation. Bone Marrow Transplant 1999; 24:1279-83.

62. Harousseau JL, Attal M, Avet-Loiseau H, et al. Bortezomib plus dexamethasone is superior to vincristine plus doxorubicin plus dexamethasone as induction treatment prior to autologous stem-cell transplantation in newly diagnosed multiple myeloma: results of the IFM 2005-01 phase III trial. J Clin Oncol 2010; 28:4621-9.

63. Roussel M, Moreau P, Huynh A, et al. Bortezomib and high-dose melphalan as conditioning regimen before autologous stem cell transplantation in patients with de novo multiple myeloma: a phase 2 study of the Intergroupe Francophone du Myelome (IFM). Blood 2010; 115:32-7.

64. Attal M, Harousseau JL, Facon T, et al; InterGroupe Francophone du Myélome. Single versus double autologous stem-cell transplantation for multiple myeloma. New Engl J Med 2003; 349:2495-502.

65. Attal M, Lauwers-Cances V, Marit G, et al; IFM Investigators. Lenalidomide maintenance after stem-cell transplantation for multiple myeloma. New Engl J Med 2012; 366:1782-91.

66. Mellqvist UH, Gimsing P, Hjertner O, et al; Nordic Myeloma Study Group. Bortezomib consolidation after autologous stem cell transplantation in multiple myeloma: a Nordic Myeloma Study Group randomized phase 3 trial. Blood 2013; 121:4647-54.

67. McCarthy PL, Owzar K, Hofmeister CC, et al. Lenalidomide after stem-cell transplantation for multiple myeloma. New Engl J Med 2012; 366:1770-81.

68. Attal M, Harousseau JL, Leyvraz S, et al; Inter-Groupe Francophone du Myélome (IFM). Maintenance therapy with thalidomide improves survival in patients with multiple myeloma. Blood 2006; 108:3289-94.

69. Morgan GJ, Gregory WM, Davies FE, et al; National Cancer Research Institute Haematological Oncology Studies Group. The role of maintenance thalidomide therapy in multiple myeloma: MRC Myeloma IX results and meta-analysis. Blood 2012; 119:7-15.

70. Vekemans MC, Michaux L, Van Den Neste E, Ferrant A. Long-term survival after allogeneic stem cell transplantation for advanced stage multiple myeloma. Br J Haematol 2014; 166:616-8.

71. Hunter HM, Peggs K, Powles R, et al; Clinical Trials Committee of the British Society of Blood and Marrow Transplantation (BSBMT). Analysis of outcome following allogeneic haemopoietic stem cell transplantation for myeloma using myeloablative conditioning--evidence for a superior outcome using melphalan combined with total body irradiation. $\mathrm{Br}$ J Haematol 2005; 128:496-502.

72. Kim SM, Kim MJ, Jung HA, et al. Comparison of the Freiburg and Charlson comorbidity indices in predicting overall survival in elderly patients with newly diagnosed multiple myeloma. Biomed Res Int 2014; 2014:437852.

73. Shah S, Vanclay F, Cooper B. Improving the sensitivity of the Barthel Index for stroke rehabilitation. J Clin Epidemiol 1989; 42:703-9.

74. Kumar SK, Dispenzieri A, Lacy MQ, et al. Continued improvement in survival in multiple myeloma: changes in early mortality and outcomes in older patients. Leukemia 2014; 28:1122-8.

75. San Miguel JF, Schlag R, Khuageva NK, et al; VISTA Trial Investigators. Bortezomib plus melphalan and prednisone for initial treatment of multiple myeloma. New Engl J Med 2008; 359:906-17.

76. Benboubker L, Dimopoulos MA, Dispenzieri A, et al; FIRST Trial Team. Lenalidomide and dexamethasone in transplant-ineligible patients with myeloma. New Engl J Med 2014; 371:906-17.

77. Durie B, Hoering A, Rajkumar SV, et al. 25 Bortezomib, Lenalidomide and Dexamethasone Vs. Lenalidomide and Dexamethasone in Patients (Pts) with Previously Untreated Multiple Myeloma without an Intent for Immediate Autologous Stem Cell Transplant (ASCT): Results of the Randomized Phase III Trial SWOG S0777 (Oral and Poster Abstracts). American Society of Hematology. 57th Annual Meeting \& Exposition. Orlando, FL: December 5, 2015.

78. Mehta J, Cavo M, Singhal S. How I treat elderly patients with myeloma. Blood 2010; 116:2215-23 
79. Palumbo A, Hajek R, Delforge M, et al: MM-015 Investigators. Continuous lenalidomide treatment for newly diagnosed multiple myeloma. New Engl J Med 2012; 366:1759-69.

80. Mateos MV, Oriol A, Martínez-López J, et al. Bortezomib, melphalan, and prednisone versus bortezomib, thalidomide, and prednisone as induction therapy followed by maintenance treatment with bortezomib and thalidomide versus bortezomib and prednisone in elderly patients with untreated multiple myeloma: a randomised trial. Lancet Oncol 2010; 11:934-41.

81. Ludwig H, Durie BG, McCarthy P, et al; International Myeloma Working Group. IMWG consensus on maintenance therapy in multiple myeloma. Blood 2012; 119:3003-15.

82. Palumbo A, Mina R. Management of older adults with multiple myeloma. Blood Rev 2013; 27:133-42.

83. Girnius SK, Lee S, Kambhampati S, et al. A Phase II trial of weekly bortezomib and dexamethasone in veterans with newly diagnosed multiple myeloma not eligible for or who deferred autologous stem cell transplantation. Br J Haematol 2015; 169:36-43.

84. Palumbo A, Bringhen S, Caravita T, et al; Italian Multiple Myeloma Network, GIMEMA. Oral melphalan and prednisone chemotherapy plus thalidomide compared with melphalan and prednisone alone in elderly patients with multiple myeloma: randomised controlled trial. Lancet 2006; 367:825-31.

85. Ludwig H, Hajek R, Tóthová $E$, et al. Thalidomide-dexamethasone compared with melphalan-prednisolone in elderly patients with multiple myeloma. Blood 2009; 113:3435-42.

86. Dimopoulos MA, Moreau P, Palumbo A, et al; ENDEAVOR Investigators Carfilzomib and dexamethasone versus bortezomib and dexamethasone for patients with relapsed or refractory multiple myeloma (ENDEAVOR): a randomised, phase 3, open-label, multicentre study. Lancet Oncol 2016; 17:27-38.

87. San Miguel I, Weisel K, Moreau P, et al. Pomalidomide plus low-dose dexamethasone versus high-dose dexamethasone alone for patients with relapsed and refractory multiple myeloma (MM-003): a randomised, openlabel, phase 3 trial. Lancet Oncol 2013; 14:1055-66.

88. Lokhorst HM, Plesner T, Laubach JP, et al. Targeting CD38 with Daratumumab Monotherapy in Multiple Myeloma. New Engl J Med 2015; 373:1207-19.

89. Moreau P, Masszi T, Grzasko N, et al. 727 Ixazomib, an Investigational Oral Proteasome Inhibitor (PI), in Combination with Lenalidomide and Dexamethasone (IRd), Significantly Extends Progression-Free Survival (PFS) for Patients (Pts) with Relapsed and/or Refractory Multiple Myeloma (RRMM): The Phase 3 Tourmaline-MM1 Study (NCT01564537) (Oral and Poster Abstracts). American Society of Hematology. 57th Annual Meeting \& Exposition. Orlando, FL: December 7, 2015.

90. San Miguel J, Mateos MV, Shah JJ, et al. 505 Pembrolizumab in Combination with Lenalidomide and Low-Dose Dexamethasone for Relapsed/Refractory Multiple Myeloma (RRMM): Keynote-023 (Oral and Poster Abstracts). American Society of Hematology. 57th Annual Meeting \& Exposition. Orlando, FL: December 7, 2015.

91. Tosi P, Zamagni E, Cellini C, et al. Thalidomide alone or in combination with dexamethasone in patients with advanced, relapsed or refractory multiple myeloma and renal failure. Eur J Haematol 2004; 73:98-103.

92. Eriksson T, Höglund P, Turesson I, et al. Pharmacokinetics of thalidomide in patients with impaired renal function and while on and off dialysis. J Pharm Pharmacol 2003; 55:1701-6. 